\title{
La Construcción Colectiva para las Mujeres (The Women's Construction Collective): Edificando para el futuro
}

Ruth McLeod

Follow this and additional works at: https://knowledgecommons.popcouncil.org/departments_sbsr-pgy

Part of the Family, Life Course, and Society Commons, Gender and Sexuality Commons, International Public Health Commons, Regional Economics Commons, and the Work, Economy and Organizations Commons How does access to this work benefit you? Let us know!

\section{Recommended Citation}

McLeod, Ruth. 1990. "La Construcción Colectiva para las Mujeres (The Women's Construction Collective): Edificando para el futuro," SEEDS no. 9. New York: Population Council. 
SEEDS es una serie de folletos creados para responder a las solicitudes recibidas de todos los sitios del mundo acerca de información sobre programas nuevos y prácticos desarrollados para y por mujeres de bajos ingresos. El objeto de estos folletos es, en consecuencia, distribuír información y estimular la creación de proyectos nuevos, basados en las experiencias positivas de aquellas mujeres que trabajan para ayudarse a si mismas y para ayudar a que otras mujeres eleven su nivel económico. Los programas que se describen en este y en otros números de SEEDS se han elegido porque les ofrecen a las mujeres la oportunidad de recibir ingresos en efectivo, de tomar decisiones y de ganar dinero; se basan en un criterio económico sensato y han solucionado con éxito los problemas que con frecuencia tienen que afrontar tales mujeres. Estos informes no pretenden dar reglas fijas, puesto que cada programa de desarrollo tendrá que enfrentar problemas un poco diferentes y contará con medios diferentes. El propósito ha sido más bien describir la historia de una idea y su implementación, en la esperanza de que las lecciones aprendidas puedan utilizarse en una gran variedad de situaciones. Se ha escrito sobre estos programas, además, para poner de presente a quienes están en posiciones directivas el hecho de que los programas para mujeres que son generadores de ingresos y están realizados por ellas, son factibles y representan un papel importante en los procesos del desarrollo.

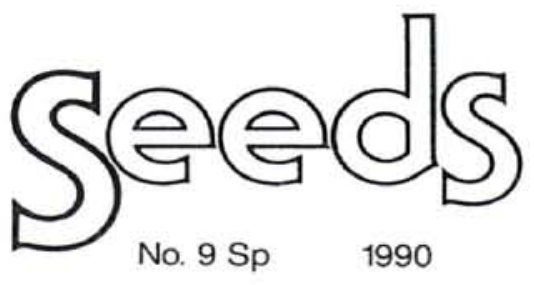

ISSN 073-6833

Copyright (c) 1990 SEEDS
El apoyo administrativo y la dirección de los proyectos de SEEDS los provee The Population Council. La política editorial la determina el SEEDS Steering Committee: Judith Bruce (The Population Council), Marty Chen (Harvard Institute for International Development). Margaret Clark (The Ford Foundation), Cecilia Lotse (UNICEF), Katharine McKee (Center for Community Self Help), Anne Walker (International Woman's Tribune Center), Mildred Warner (Cornell University) y Ann Leonard (Editor).

La traducción de esta edición de SEEDS al español fue subven. cionada por la Fundación Rockefeller.

Las exposiciones y los puntos de vista expresados en esta publicación son total responsabilidad del autor y no de las organizaciones que proveen su apoyo a SEEDS. 


\title{
La Construcción Colectiva para las Mujeres (The Women's Construction Collective): Edificando para el Futuro
}

\author{
Relato de Ruth Mcleod
}

\section{Introducción}

La isla de Jamaica, en el Mar Caribe, tiene una población aproximada de dos millones de habitantes, más de la mitad de los cuales vive en áreas urbanas; de estas, la más grande es Kingston, la ciudad capital. La sofisticación de la isla se ve claramente en los altísimos edificios que forman el centro financiero de Kingston y en los lujosos hoteles que se levantan en la costa norte de la isla. Sin embargo, hay otras indicaciones del rápido desarrollo urbano que son también visibles: establecimientos de colonos y de caseríos urbanos, que se caracterizan por el alto nivel de desempleo, la fuerte afiliación a determinados partidos politicos y un bajo nivel de vida. En estas áreas de población muy densa se presentan problemas de indole social, económica y politica, a cuya complejidad tienen que enfrentarse los encargados de planear el desarrollo, especialmente quienes se concentran en mejorar la situación de la mujer.

Dado el hecho de que por lo menos en una tercera parte de los hogares de la isla y en la mitad de las familias que viven en las áreas urbanas la cabeza del hogar es una mujer, y considerando que la rata de desempleo es más del doble en las mujeres que en los hombres, no debe sorprendernos que la posición de la mujer en la sociedad jamaicana y su papel en el proceso del desarrollo atrajeran considerable atención durante la Década Internacional de la Mujer (International Decade of Women), 1975-1985.

Este número de SEEDS enfoca un programa creado para integrar a la mujer de ingresos bajos a la industria de la construcción en Jamaica. En dos años, hubo 34 mujeres que recibieron el entrenamiento básico del programa y los cursos más avanzados. Más del 90 por ciento de estas mujeres se han empleado; la mayoria son carpinteras y albañiles. La historia de cómo se identificó este campo como fuente potencial de ingresos para la mujer, y cómo se desarrolló el proyecto respondiendo a las circunstancias siempre cambiantes, nos presenta muchas lecciones útiles. Este proyecto será de especial interés para quienes estén tratando de identificar áreas de trabajo en las cuales sea posible la participación de la mujer. También les ayudará a preparar a la mujer para que entre a áreas de trabajo de las cuales ha estado tradicionalmente ausente. 
En julio de 1981, el Population Council inició un programa titulado "La Mujer, los Hogares de Bajos Ingresos y los Servicios Urbanos en la América Latina y el Caribe". El propósito fue lograr que las necesidades prevalentes entre las mujeres de ingresos bajos se consideraran en los planes urbanos ya existentes, mediante la creación de grupos que trabajarian localmente en tres áreas metropolitanas: Kingston, en Jamaica; Lima, en Perú; Ciudad de México, en México. Estos grupos, que se denominaron Working Groups, consistieron de: planeadores urbanos, especialistas en investigación y estadisticas, expertos en desarrollo y especialistas en ciencias sociales. Esta mezcla estimuló el crecimiento de nexos entre las burocracias de los gobiernos, las entidades académicas y las organizaciones de desarrollo comunal. Gracias al trabajo de estos grupos fue posible reunir toda clase de información sobre la gente probre urbana; y se identificaron así, en forma realista, las prioridades de los planes de acción.

El Population Council, mediante un acuerdo de cooperación con la Oficina de Vivienda y Desarrollo Urbano (Office of Urban Development and Housing) perteneciente a la Agencia de Desarrollo Internacional de los Estados Unidos (USAID) ${ }^{\star}$, asignó a cada uno de los Working Groups una modesta suma que podia usarse para financiar pequeños proyectos, tales como: la documentación de programas ya en acción; la experimentación de nuevas formas de servicios; un nuevo análisis de datos existentes; y la iniciación de información nueva, con énfasis en la calidad. La información y las sugerencias de procedimiento emanadas de los Working Groups, fueron diseminadas localmente por los grupos mismos; internacionalmente, a través de las publicaciones de los reportes de trabajo lo mismo que mediante reuniones y seminarios coordinados por el Population Council.

\footnotetext{
*Este trabajo continúa en una segunda fase de 1985 a 1987, con la ayuda de la Oficina de Mujeres en Desarrollo de USAID. La Women's Construction Collective de Kingston es uno de los proyectos de más éxito llevado a cabo por el Working Group de Kingston como parte de este programa total.
}

\section{La Identificación de las Necesidades}

En mayo de 1983, el Working Group de Jamaica-que consistía aproximadamente de una docena de planeadores, investigadores y especialistas en desarrollo comunal-aprobó un proyecto experimental que proponía dar entrenamiento a mujeres desempleadas y conseguirles empleo al nivel de obreros en la industria de construcción de Jamaica. ¿Por qué proponer mujeres para la construcción? Hubo tres factores determinantes para que el Working Group decidiera llevar a cabo el proyecto de entrenar e integrar a la mujer en la industria de construcción:

(1) A mediados de 1982, la industria de construcción estaba en su apogeo. Según el Instituto de Planeación de Jamaica, de 1981 a 1982 esta industria creció un 14,8 por ciento; y a mediados de 1983, estaba contribuyendo 6,1 por ciento al producido total de las industrias de la isla (GDP) y dando empleo a 32.000 personas. El presidente de Masterbuilders, una organización que-representa a los contratistas de la industria de construcción, había predicho que iban a necesitarse anualmente, durante los 3 años siguientes, 5.000 expertos trabajadores más. Pero de los 32.000 ya empleados, sólo 800 eran mujeres. Y entre estas, sólo 100 tenían categoría de profesionales; 600 hacian trabajo de asistentes 0 ayudantes y 100 hacian trabajos manuales rudimentarios. Por otra parte, las mujeres no estaban siquiera representadas en las estadísticas oficiales del gobierno como trabajadoras en este gremio de la industria.

(2) En efecto, a la mujer se le había excluido de participar en el programa del gobierno para entrenamiento en construcción al nivel del gremio, debido a la implementación de nuevas normas de entrenamiento. Antes de 1983, había en la isla más de 100 centros para entrenamiento industrial que ofrecian clases para hombres y mujeres durante el día. Se estima que 1.000 mujeres recibieron entrenamiento en construcción de 1976 a 1980; sin embargo, fueron pocas las que encontraron trabajo en esa industria. En 1983, el gobierno hizo un 


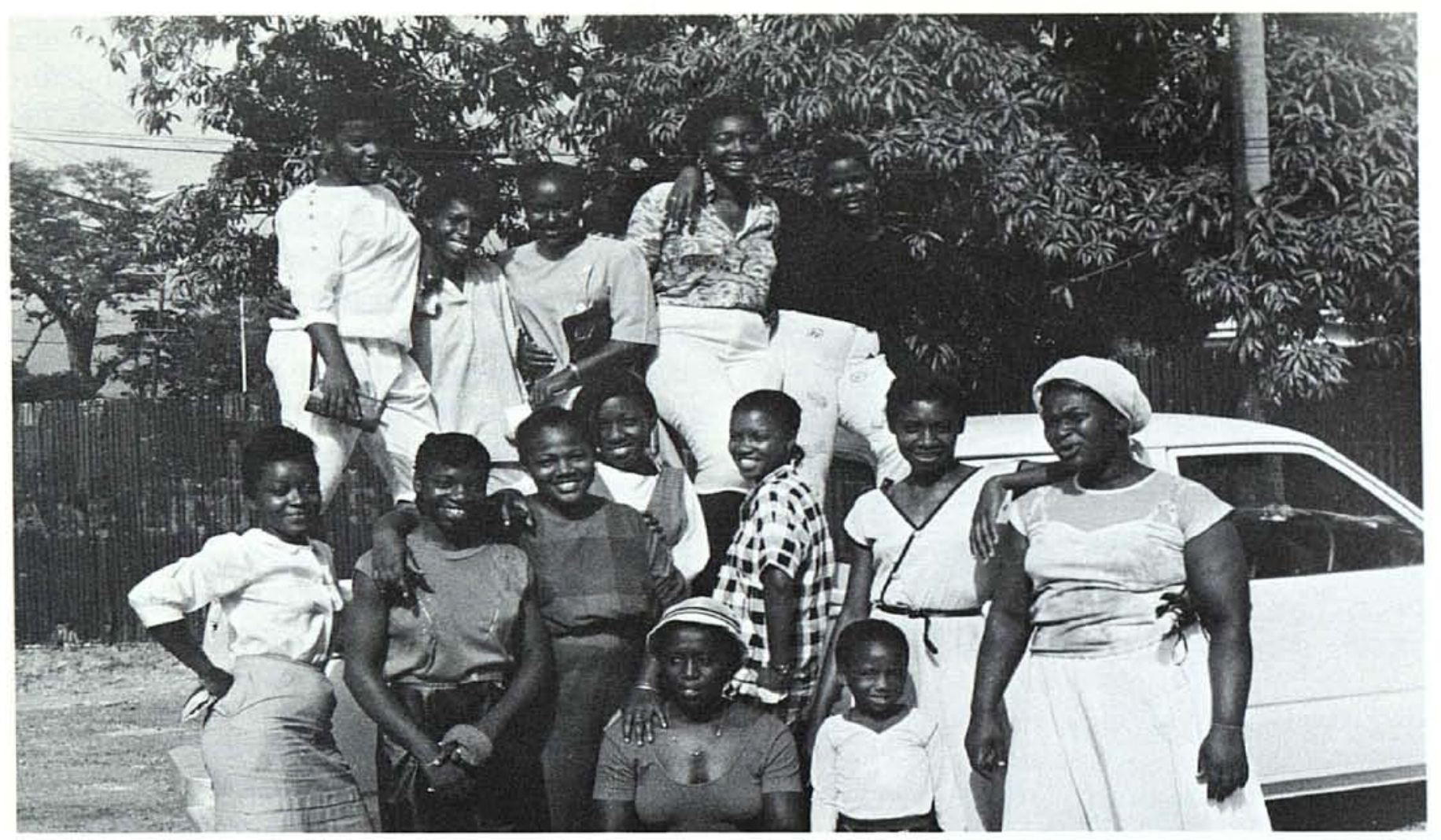

cambio en el sistema; decidió utilizar un número menor de centros de entrenamiento, pero cada uno de estos funcionaba en un edificio más grande que los anteriores y ofrecia entrenamiento y residencia únicamente para hombres. En teoria, sin embargo, se admitian mujeres como estudiantes durante el día; pero hasta diciembre de 1985, ni una sola mujer había sido entrenada en construcción bajo este sistema.

(3) Se temía que la alta rata de desempleo entre las mujeres jóvenes pudiera afectar la disminución de la fertilidad, que era lo que el Consejo Nacional de Planificación Familiar se proponía con sus servicios gratuitos de planificación familiar, especialmente enfocados hacia las adolescentes. Se había observado una definitiva correlación entre la mujer desempleada y la fertilidad, especialmente en los barrios donde se agrupan las gentes más pobres; porque en estos barrios, el papel de "baby mother" (así se llama a las madres en Jamaica, como también es típico referirse a los padres como "baby fathers") era con frecuencia la única posición adecuada que podía lograr una mujer joven.

El Working Group encontró que este proyecto propuesto era particularmente intere- sante, porque tendria que enfocar tanto los problemas de la industria como los comunales; y presentaba entonces la posibilidad de estrechar los nexos entre el entrenamiento y la consecución de trabajo para la mujer. Al mismo tiempo, iba a ofrecer la oportunidad de reconocer el papel de la mujer en áreas de trabajo de las cuales había estado tradicionalmente ausente. Esto último merecia alta prioridad, puesto que no habia información estadística sobre mujeres que hubieran recibido antes entrenamiento en materias de construcción, ni sobre los resultados de sus tentativas para trabajar en ese campo. En consecuencia estas mujeres, ausentes de las estadísticas, no podian servir como ejemplo positivo para la industria de la construcción ni servir de ejemplo para otras mujeres. Como dicha información era inexistente, quienes desarrollaban los planes oficiales para programas de entrenamiento tendían a asumir que las mujeres no estaban interesadas en el campo de la construcción o que, si lo estaban, no podian conseguir trabajo en ese campo.

\section{Los Cimientos del Proyecto}

El proyecto se inició con la formación de un grupo que iria a servir de vehículo para el desarrollo de un programa de entrenamiento diseñado para las necesidades especificas de 
las mujeres de ingresos bajos, jóvenes y desempleadas. Este programa de entrenamiento ofrecía a las mujeres no sólo el aprendizaje del oficio sino la ayuda para darse cuenta de cómo es la realidad en ese tipo de empleo; es decir que incluiria las reacciones de los hombres y a la vez el desarrollo de estretegias para vencer los temores y obstáculos que han de presentarse al trabajar en un campo totalmente dominado por el hombre.

Los planes iniciales se basaron en la selección de diez mujeres del sector llamado Western Kingston. Estas se someterian a un programa de entrenamiento intensivo y se les encontraria trabajo; se las vigilaria muy de cerca para que, durante un periodo de 15 meses, sus experiencias pudieran documentarse fotográficamente y también por escrito. Esta documentación serviría para reforzar la propuesta de que se estableciera un programa gubernamental de entrenamiento para la mujer (Government Skills Training Program).

El proyecto fue propuesto y luego coordinado por Ruth Mcleod, quien había sido originalmente una consultora para desarrollo de recursos humanos en la Incorporated Masterbuilders Association of Jamaica (IMBA), una organización que representa cerca del 80 por ciento de los contratistas para edificaciones en la isla. Su trabajo con la IMBA era servir de consejera para el gobierno en lo relativo al plan de estudios para entrenamiento en cons- trucción. Más tarde pasó a ser directora administrativa (Managing Director) del Construction Resources and Development Center (CRDC), una organización para investigación y desarrollo, independiente y sin propósito de lucro; esta organización se formó con representantes de siete asociaciones profesionales y laborales, entre las cuales había arquitectos, ingenieros, topógrafos y miembros de las uniones laborales.

Hubo problemas que fue necesario afrontar desde el principio. Uno de ellos tenia que ver con los 66 grupos de trabajadores que la industria de construcción de Jamaica reconocia, entre los cuales había muchos con tres categorias diferentes. ¿En cuál de estos grupos se encontrarian las mejores oportunidades de lograr trabajo? Esta pregunta se complicaba más aun al observar las formas como tradicionalmente se daban los empleos. Como los subcontratos son un factor que prevalece en la industria de construcción en Jamaica, del 70 al 100 por ciento de todo el trabajo obrero hecho en una localización se lleva a cabo a través de subcontratistas, sobre la base de una tarea específica. La mayoría de los subcontratistas trabajan con cuadrillas de obreros no estructuradas, cuyo personal puede cambiar de un trabajo a otro. Los subcontratistas no tienen, por lo general, una dirección comercial que se conozca ni, por supuesto, teléfonos o secretarias. La admisión a estas cuadrillas del

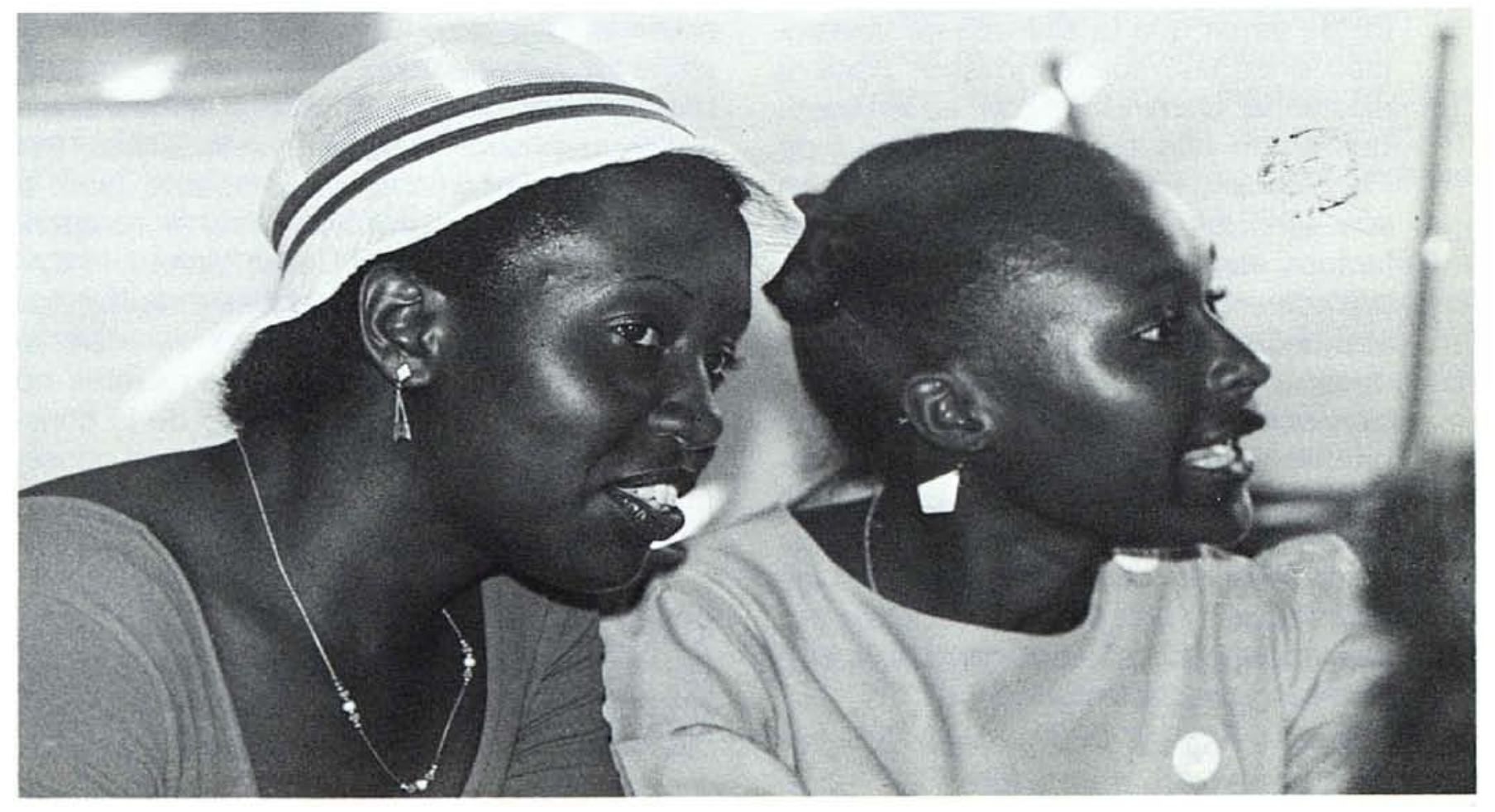


gremio se logra a través de una serie de amigos, parientes y obreros que se han conocido entre si en trabajos anteriores. Obviamente, lograr entrada a esta red humana no iba a ser fácil, sobre todo si se pensaba en seguir los medios establecidos y penetrar a través de relaciones femeninas.

El resto del trabajo de construcción se lleva a cabo, sin embargo, contratando directamente al trabajador y pagándole una tarifa diaria. Así, el contratista principal generalmente emplea supervisores del trabajo en el local, supervisores del tiempo trabajado, operarios de plantas y de equipos, guardas de seguridad, ayudantes del gremio y obreros diversos. Los ayudantes del gremio se seleccionan generalmente dentro del grupo de obreros, y es posible que se les asigne un trabajo especifico con subcontratistas del gremio a medida que la construcción progresa. Los encargados de la planeación de este proyecto consideraron que si las mujeres pudieran encontrar empleo como ayudantes de obreros, esto les daría acceso a la red de los subcontratistas; y esto, a su turno, les daría la oportunidad de adquirir entrenamiento durante el trabajo mismo, incrementando así sus conocimientos en el campo de la construcción mientras ganaban un salario.

Otra complicación evidente era la gran influencia de las rivalidades políticas en la industria de la construcción en Jamaica. Si una construcción está en un área que se afilia a un partido político determinado, los pertenecientes a ese partido esperan que automáticamente se les concedan privilegios en el trabajo. Esta situación está respaldada por representantes oficiales o semi-oficiales; de suerte que quienes estén afiliados a otros partidos políticos entran tomando un riesgo muy grande, a no ser que tengan una especialización poco común o una relación estrecha con el contratista principal. En la iniciación del grupo que se llamó Women's Construction Collective fue necesario darse cuenta de que, al desarrollar el programa, tendría que afrontarse la violencia proveniente de esta política territorial.

Un problema adicional fue el poder calcular con precisión los fondos que serían necesarios para llevar a cabo el proyecto. El presupuesto inicial que presentó el Working Group fue de US\$8.000 para cubrir un periodo de 15 meses. Con esta suma habria que hacer gastos de instalación e instructores;

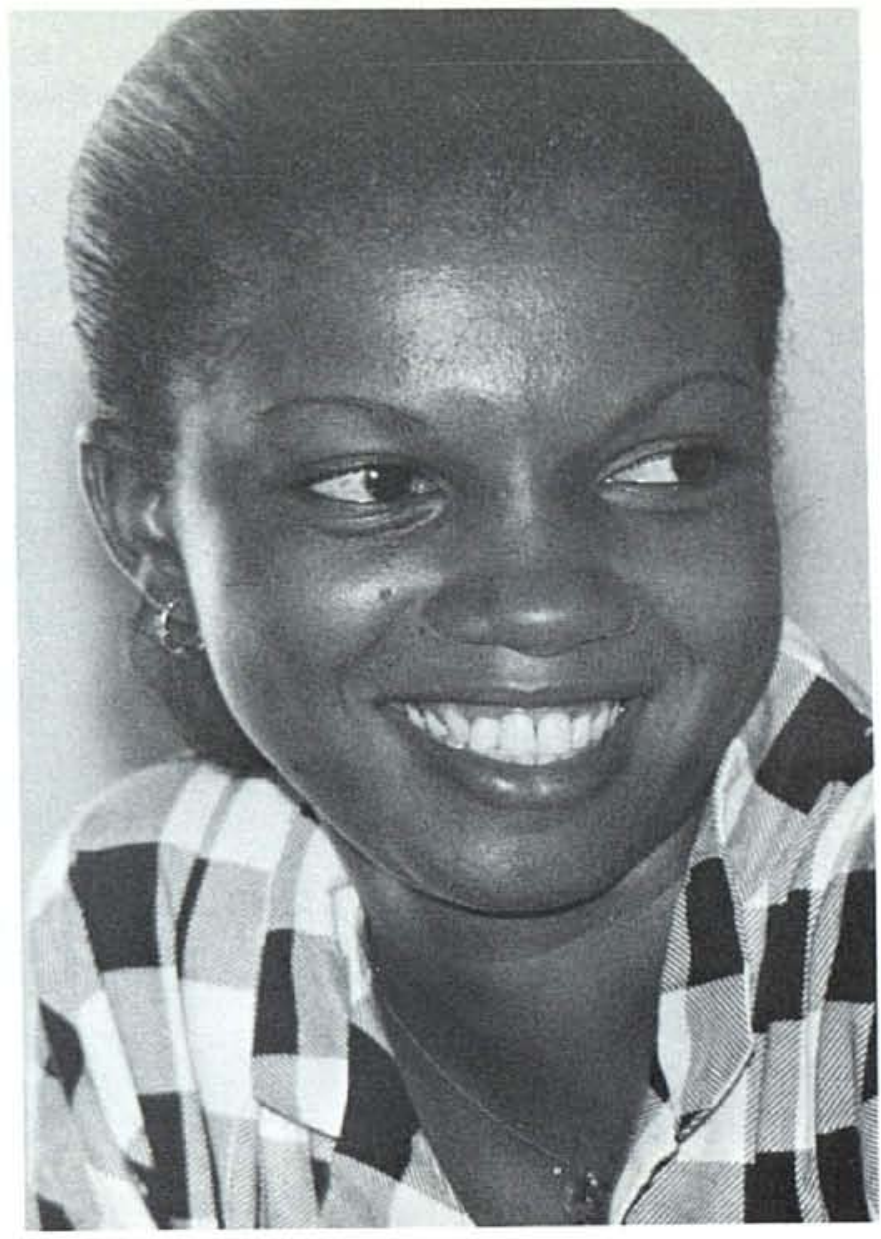

materiales de trabajo y transporte; más el proceso de conseguir los empleos, lo cual requeriría tiempo para investigar y para establecer los contactos necesarios. Cualquier cambio o desviación en estos planes podría representar la necesidad de conseguir fondos adicionales.

El primer paso en el desarrollo del programa fue localizar una base apropiada para el entrenamiento. Esta tarea estuvo a cargo de la coordinadora del programa, dada su experiencia en el campo y su conocimiento de las agencias que podian proporcionar tal entrenamiento. El centro CRDC con frecuencia desarrolla programas experimentales de entrenamiento en el ramo de construcción, para trabajadores adultos y a menudo en cooperación con el Vocational Training Development Institute (VTDI). EI VTDI es una agencia encargada de dar entrenamiento para instructores vocacionales en Jamaica y en otras islas del Caribe. También ofrece cursos cortos para incrementar los conocimientos en una gran variedad de áreas industriales. El hecho de trabajar con el CRDC y con el VTDI fue de gran beneficio en el desarrollo del entrenamiento. 
El segundo paso fue la búsqueda de las participantes potenciales. Un miembro del Working Group, el Community Liaison Officer, un oficial de vinculación de la comunidad para el área de Western Kingston, se encargó de seleccionar a las participantes. Todas tenian que vivir en el área de Western Kingston Ilamada Tivoli Gardens, una comunidad desarrollada durante un plan de mejoramiento llevado a cabo en los años sesentas, cuando el partido laboral Jamaican Labour Party (JLP) estaba en el poder. Consiste de 1.000 unidades de vivienda, la mayoría de las cuales son bloques de cuatro pisos con apartamentos individuales y terrazas. Esta comunidad de Tivoli Gardens apoya fuertemente al actual Prime Minister. Se caracteriza por alta rata de desempleo femenino, de preñez en las adolescentes y de mujeres jóvenes que tienen que sostener a sus hijos. Las mujeres fueron elegidas para participar en la Collective (Women's Construction Collective), basándose en exámenes de conocimientos generales y aritméticos tanto como en informaciones provenientes de los líderes del club local para la juventud.

Se decidió seleccionar mujeres de la misma comunidad o barrio, porque esto ofrecía una base fuerte de cohesión entre las mujeres del grupo. Cada una iba a entender los problemas y las limitaciones de las otras; así podrian ayudarse mutuamente en asuntos de orden práctico tales como el cuidado de los niños. Además serian conocidas de la Community Liaison Officer cuyo papel, especialmente durante las primeras etapas del proyecto, fue muy importante. Por ejemplo si una mujer tenía problemas con su "baby father" (el padre de sus niños), esta coordinadora le hablaria tanto al hombre como a la mujer; y, por otra parte, se encargaria de que la comunidad estuviera siempre informada acerca del proyecto.

La mayoría de las mujeres reclutadas ori. ginalmente pertenecía también al Ultimate Youth Club, un club juvenil de Tivoli. Este club está manejado principalmente por hombres que, por fortuna, comprenden la importancia de ofrecer nuevas oportunidades de empleo a las mujeres; en consecuencia, desde el comienzo apoyaron el proyecto, ayudaron constantemente a organizar eventos para conseguir fondos e inclusive asistieron a algunas de las reuniones iniciales de la Collec- tive. El apoyo que los miembros más influyentes de la comunidad ofrecieron a las mujeres fue de importancia básica; gracias a éste se logró que el atentado de penetrar un terreno dominado por el hombre, pasara de ser posible a ser legítimo. Los individuos más prestantes del Youth Club y la Community Liaison Officer, comenzaron a hablar del proyecto en toda la región y a referirse a las mujeres de la Collective como pioneras y como ejemplos de fortaleza y determinación.

\section{Entrenamiento}

En términos generales, lo que se relaciona con entrenamiento en este proyecto puede agruparse en cuatro fases:

- En octubre de 1983, la Fase I comienza en la agencia VTDI con 10 mujeres.

- En enero de 1984, la Fase II comienza con cinco mujeres que se inician como parte del Programa de Mantenimiento de edificios (Building Maintenance Program) del centro CRDC.

- En mayo de 1984, la Fase III comienza con 15 mujeres reclutadas en nuevas comunidades que se eligieron.

- En junio de 1984,-Fase IV-cuatro mujeres más recibieron entrenamiento en el CRDC.

Con base en las investigaciones iniciales, en el nivel de experiencia de las mujeres que eran miembros de la Collective y en los fondos disponibles, se decidió que las participantes comenzaran con un programa de cinco semanas de entrenamiento en albañilería y carpinteria. Este consistiria de tres componentes: tareas prácticas, lecciones en el salón de clase y conferencias dictadas por expertos en la industria. A este entrenamiento básico le seguiría una serie de programas progresivos que se desarrollarian a medida que fuera necesario.

Las diez mujeres que llegaron muy temprano, una mañana de septiembre de 1983, a la agencia VTDI en el Departamento de Construcción de Kingston, no parecian ni remotamente un grupo de obreros de construcción en potencia. Vestian zapatos como para salón de baile, medias muy transparentes $y$, con pocas excepciones, reian nerviosamente y se cubrían la boca con las manos cuando se les pedia que se presentaran a los instructores. Su 


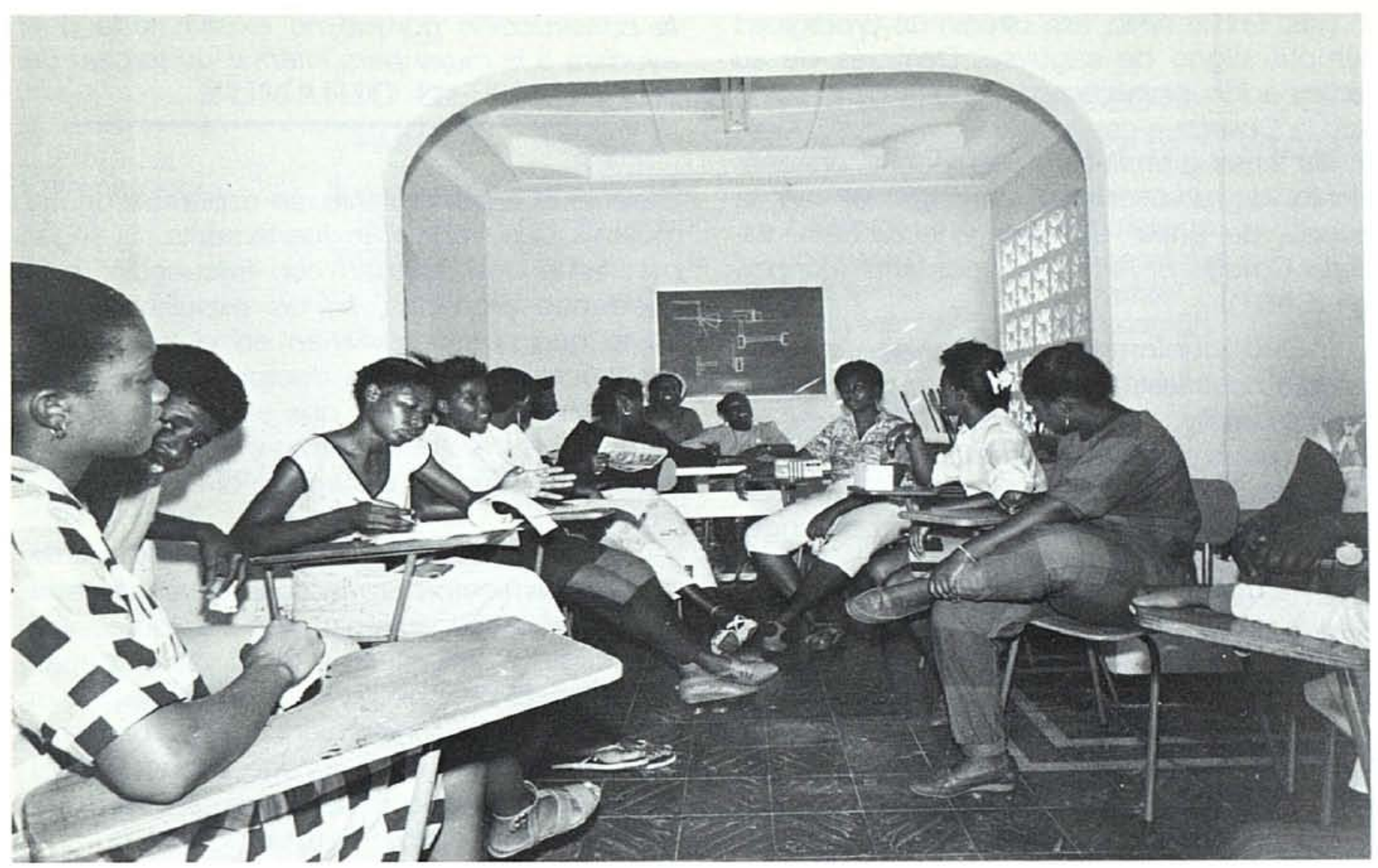

edad oscilaba entre los 17 y los 25 años, todas venian de Tivoli Gardens y habían completado por lo menos hasta el noveno año de escuela. Todas sabian leer, escribir y contar; su aspecto físico era fuerte y la mayoría había tenido al menos un hijo antes de llegar a los 17 años. A ninguna se le había ocurrido buscar trabajo en la industria de la construcción. No era fácil imaginarse que en un término de cinco semanas, estas mismas mujeres iban a estar preparadas para empezar a trabajar como ayudantes de gremio en grandes obras de construcción. Pero el hecho es que iban a tener la preparación básica y los conocimientos de terminología necesarios en construcción. Y si tenían éxito en la consecución de un trabajo, iban a lograr la garantía de un salario semanal equivalente al doble del salario mínimo, más la oportunidad de convertirse en trabajadoras competentes dentro del gremio.

El entrenamiento comenzó con una tarea de extraordinario valor práctico: el edificio de la agencia VTDI no tenía ni baño ni lugar apropiado para que las mujeres se cambiaran de ropa. En consecuencia, la primera labor que se les asignó fue que hicieran una división en el cuarto de los hombres para que ellas tuvieran su propio baño y lugar para cambiarse. Durante esta faena se arruinaron muchas medias de nilón y en pocos días pudo apreciarse un cambio en la apariencia de las mujeres. Los "jeans" y los zapatos-tenis reemplazaron faldas y sandalias, y comenzó a trabajarse en serio.

Además de la práctica manual, en el salón de clase se enseñaban otros temas como la manera de medir con exactitud, la aproximación de cálculos y las cantidades correctas para hacer mezcla o argamasa y concreto. Cada mujer tenia que construír una pared completa de concreto usando un palustre, una tabla portamezcla, una plomada y un nivel de burbuja. La pared tenía que levantarse correctamente y estar prolijamente terminada. Fuera de eso, la mujer tenia que serruchar madera para hacer una armazón y construir correctamente un taburete o banquillo.

Los hombres y mujeres que les daban conferencias trataban tópicos muy diversos. Una mujer contratista habló sobre el aspecto práctico de trabajar como mujer en una construcción. Se discutieron las preguntas que surgieron, tales como el cuarto para cambiarse, cómo lograr y mantener el respeto de los hombres y cómo tratar los cólicos menstruales. Esta mujer maneja seis compañias propias, desde una que se ocupa de construír y hacer contratos, hasta una planta de cilindros 
de gas. Por lo tanto, ella ofreció un prodigioso ejemplo, digno de seguirse. Después de su participación inicial como instructora, patrocinó para la Collective casillas de exhibición y venta en las ferias gremiales y respaldó el entrenamiento de una de las participantes en la escuela de artes, ciencias y tecnología, llamada College of Arts, Sciences and Technology (CAST).

Otro conferencista, que es un prominente contratista, ha dado también su permanente apoyo a la Collective. Después de hablar de las diferentes carreras y opciones en construcción, condujo un recorrido de todas las participantes a varias oficinas de ingenieros, topógrafos, agrimensores y constructores; además las llevó a una fábrica de componentes para construcción y a por lo menos tres áreas en que se llevaban a cabo construcciones.

Al llegar a la mitad del entrenamiento, la mayoria de las mujeres habían cambiado por completo la idea que tenían de la industria en cuestión. Así lo expresó una de las participantes: "Yo creia que era sólo poner ladrillos y abrir zanjas; nunca me había dado cuenta de que se trataba de tantos otros trabajos...j hasta trabajo de computadoras!"

Pauline abandonó la escuela dos meses antes de graduarse porque estaba esperando su primer hijo. Después entró a una escuela de comercio, pero tuvo que dejarla porque su "baby father" se enfermó. Más tarde, cuando él se fue a los Estados Unidos, Pauline quedó totalmente a cargo de mantener a su hijo $y$ comenzó a buscar trabajo. Ella había oído de la Collective porque "todas sus amigas hablaban de eso" y decició unirse al segundo grupo de participantes en la Fase II.

Pauline ha trabajado durante 10 meses en un gran proyecto de construcción, levantando un edificio nuevo para entrenamiento en construcción. Si ella fuera hombre, podría asistir como alumno residente; pero como es mujer, no puede hacerlo.

Cuando se le preguntó a Pauline qué opinaba sobre su propia experiencia en este campo, respondió: "Para mi ha sido magnífica. Ofrece muchas más posibilidades de lograr una carrera que las que ofrecía la costura en que me ocupaba antes. Si no hubiera sido por la Collective, yo nunca me habría asociado con la construcción porque no existía nada que ayudara a la mujer para intentar un trabajo de esta clase."

Durante el entrenamiento, se esperaba de las mujeres que trabajaran fuertemente. Si llegaban tarde o si faltaban con frecuencia, o si quedaban preñadas, se las expulsaba. Era obvio que no sobrevivirían en el trabajo de construcción si no eran disciplinadas y físicamente fuertes. Lo único que se les daba a las participantes era el almuerzo y el dinero necesario para pagar el transporte diario de ida y regreso.

Cuando se terminó el primer programa de entrenamiento para las participantes de la Fase I, el entrenamiento que recibieron los miembros de la Collective tomó varias formas diferentes. El objetivo principal siguió siendo el desarrollo de los conocimientos, en el nivel y la categoria que la industria necesitaba. Los tres componentes básicos del entrenamiento permanecieron idénticos. Pero a medida que se reclutaron mujeres de otras áreas, el programa tuvo que adaptarse tanto a las necesidades de estas como a los requisitos cambiantes de la industria, para aprovechar así al máximo los recursos disponibles.

\section{Colocación}

Mientras las primeras diez mujeres se entrenaban, se llegó a un acuerdo con los contratistas: se comprometieron a colocarlas como ayudantes del gremio en un proyecto del gobierno planeado para mejorar las condiciones del mercado. Este proyecto incluía la restauración de varios mercados ubicados en el centro comercial de Kingston, los cuales eran usados por vendedores (en su mayoría mujeres) que traian productos agrícolas de todos los sitios de la isla. Las instalaciones del mercado eran muy viejas; por lo tanto el proyecto estaba enfocado hacia la mejoría de las condiciones sanitarias, la iluminación, la ventilación y el área de los puestos de venta. Como el arquitecto principal era miembro del Working Group y el proyecto estaba ubicado en un área que tenía la misma afiliación política de Tivoli, era de presumir que el ingreso de las mujeres no encontraría resistencia en el aspecto político. El contratista habia aceptado incorporar a las mujeres en el grupo de traba- 


\section{SUMARIO DE ENTRENAMIENTO Y COLOCACION}

FASE I

Entrenamiento

Inicial

5 semanas 12 semanas
tiempo
completo
VTDI

10

Barrio Nannyville

Barrio Glengoffe

Para colocar

No terminaron

Albañiles

Carpinteras

Plomeras

Electricistas

Fundición de acero

Pintoras

1
FASE III

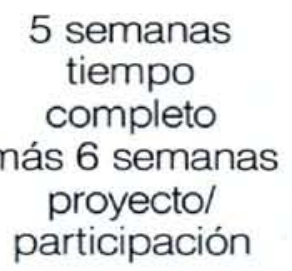

FASE IV

TOTAL
5

6
4
5

$\begin{array}{lll}2 & 1 & 1\end{array}$

3

1

9

2

\author{
12 semanas \\ medio tiempo \\ más 6 semanas \\ proyecto/ \\ participación
}

1

1

0

4

1

3

22

7

5

19

3

1

3

1

3 jadores, pagarles lo mismo que a los hombres que eran ayudantes del gremio y adjudicarles trabajo con los subcontratistas. Desafortunadamente, después de tres semanas de comenzado el programa de entrenamiento hubo grandes cortes en el presupuesto del gobierno, y esto obligó a posponer indefinidamente el proyecto del mercado. O sea que, en términos de empleo, el programa regresaba al punto inicial.

El entrenamiento terminó a finales de noviembre y la época navideña hizo más difícil la consecusión de este tipo de empleo. Los miembros de la Collective aceptaron la decisión de reunirse los domingos en el centro comunal de Tivoli, pero a medida que el tiempo pasaba la depresión aumentaba. Sin embargo, pronto surgió en la Collective la idea de una nueva estrategia: ofrecerse para trabajar en contrucción en términos solamente de prueba y sin costo alguno para el contratista. Si la prueba era satisfactoria y a la mujer se le ofrecía trabajo a largo plazo, se le pagaría el período de prueba. $Y$ si, por otra parte, la prueba no era satisfactoria, el contratista no estaría obligado a pagarle nada a la aspirante.

A un buen número de contratistas se les preguntó si querían entrevistar a miembros de la Collective. A mediados de enero, la contratista que había participado en el entrenamiento respondió; dos mujeres serían aceptadas por el periodo de prueba en un proyecto de vivienda ubicado en el área Spanish Town, que está a 12 millas de Kingston. El lunes siguiente se presentaron alli dos mujeres con excelentes evaluaciones técnicas dadas por la agencia VTDI; llevaban palustres nuevos y cintas métricas que les había proporcionado la Collective. $\mathrm{Y}$ al terminar la semana, ya les habian dado empleo permanente.

Poco después, el contratista que habia dado una conferencia al grupo, ofreció tomar a prueba cuatro mujeres en un proyecto de viviendas para clase media situado en Kingston. Estas lograron su contrato casi inmediatamente. Por fin parecía eliminada la dificultad de conseguir trabajo. $Y$, en efecto, todas las mujeres que se presentaron después consiguieron trabajo.

Un problema emanado de esta estrategia fue el de decidir qué mujer se elegía para que se presentara a la entrevista. Al comienzo, como eran sólo 10 mujeres, fue fácil elegir basándose en la eficiencia técnica demostrada durante el entrenamiento. Pero a medida que 
la Collective comenzó a ser más heterogénea, se impuso la necesidad de establecer un sistema. De ahi en adelante, las mujeres que no tenian ninguna experiencia de trabajo fueron las primeras que se consideraron para ser entrevistadas en un trabajo.

(Un atractivo importante del ramo de construcción como posible campo de empleo ha sido la alta remuneración, aún al nivel de principiante. Por ejemplo, los ayudantes de albañilería y de carpintería a nivel de principiantes ganan un salario de $\mathrm{J} \$ 100$ por semana, mientras que el salario mínimo oficial en Jamaica es de J\$56 por semana y el pago promedio para una mujer que hace trabajos domésticos es de J\$50 por semana. Una mujer de la Collective se empleó como pintora industrial con un salario que comenzó en J\$500 por semana. Lo que usualmente puede esperar un ayudante de construcción es que le paguen J\$125 por semana después de un año. En términos generales, los sueldos mensuales de los miembros de la Collective van de $\mathrm{J} \$ 400$ a $\mathbf{J} \$ 2.000$. En enero de 1986, J\$56 = US\$10.)

\section{Expansión}

Pronto se hizo evidente que la demanda de trabajadoras iba en aumento, lo cual justificaba la expansión del proyecto. En enero, cinco mujeres más se unieron a la Collective, pero aun asi habia más trabajos disponibles que mujeres para llenarlos. En febrero de 1984 se le pidió a la Collective que facilitara de 10 a 15 mujeres para la construcción de una fábrica. Sin embargo, para ensanchar la Collective se necesitaban más recursos, tanto financieros como humanos. Por lo tanto, era preciso tomar ciertas decisiones de carácter crítico. Ejemplos:

- ¿Cómo iban a seleccionarse las participantes?

- ¿Qué clase de organización estructural seria necesaria para que la Collective pudiera funcionar con mayor número de miembros?

- ¿Cómo podría lograrse que la Collective fuera independiente y pudiera sostenerse a sí misma?

La Collective habria podido aumentar el número de sus miembros reclutando mujeres en Tivoli. Pero esto habría ocasionado que se la indentificara con el partido político pre- dominante en Tivoli, el Jamaica Labour Party (JLP), y en consecuencia estaría expuesta a que se le hicieran cargos de favoritismo político; esto, a su turno, podría amenazar sus perspectivas de desarrollo a largo plazo. Otra alternativa podria haber sido anunciar abiertamente su solicitud de participantes. Esta opción se rechazó porque la experiencia le había demostrado al Working Group que si se partía de una fuerte base comunal aumentaban las posibilidades de que los grupos de mujeres fueran cohesivos. La tercera opción fue seleccionar otras comunidades o barrios para reclutar mujeres.

La Collective finalmente decidió que lo mejor era buscar otros barrios, con diferentes afiliaciones políticas, para las nuevas reclutas. Esta propuesta se le presentó a la Canadian International Development Agency (CIDA). Mientras la propuesta era considerada, una fundación local, la Grace Kennedy Foundation, dio una ayuda a corto plazo de $\mathbf{J} \$ 5.000$.

Al hacer la decisión de extender el proyecto a otras comunidades, era preciso definir el criterio para llevar a cabo la selección.

- Las comunidades tendrían que caracterizarse por su alto porcentaje de desempleo femenino, especialmente entre las mujeres más jóvenes que sostienen a sus hijos.

- Tendrían que demostrar, en forma evidente, el liderazgo de la comunidad y su compasión humana, tanto en sus regulaciones como en su conducta social.

- Tendrian que tener un lugar disponible para las reuniones de las mujeres que ingresaran a la Collective.

- Tendrían que estar a una distancia razonable por autobús del centro de entrenamiento y de las áreas en que los proyectos de construcción ofrecen trabajos.

- Lo ideal sería que una de las comunidades estuviera claramente identificada con el partido político de oposición, que es el People's National Party (PNP), como lo estaba Tivoli con el JLP.

La decisión final de expandirse coincidió con la llegada de una nueva persona voluntaria que ofreció ayudar a manejar el proyecto a través del año siguiente. Su trabajo principal seria la supervigilancia de hasta nueve diferentes proyectos de construcción ubicados geográficamente en áreas separadas. 


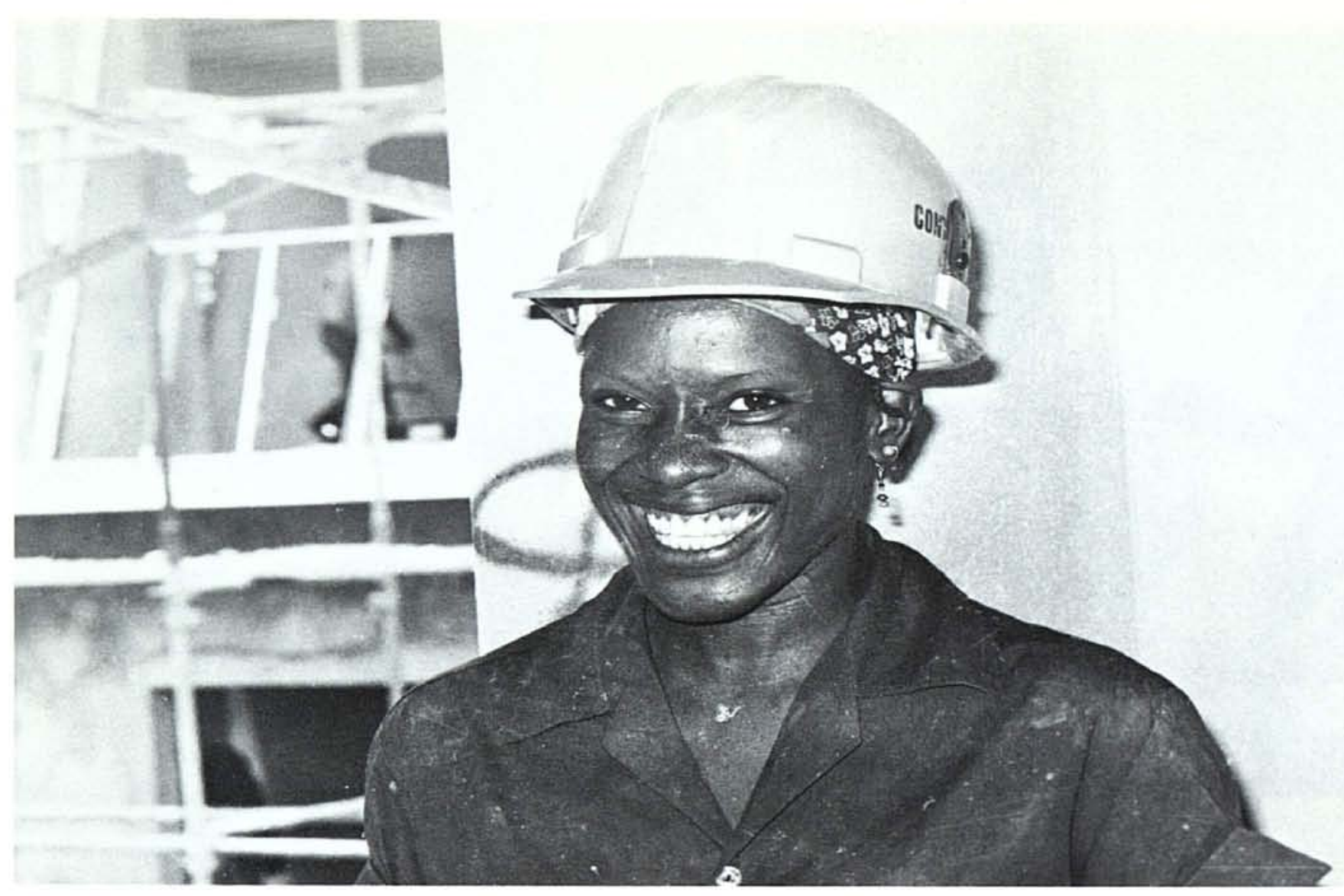

En mayo, los fondos de la agencia CIDA ya habian llegado, el nuevo gerente adicional se habia instalado y la ampliación podía comenzar. Dos nuevas comunidades se eligieron para participar en el proyecto de la Collective: Nannyville, una colonia de viviendas construida en los años setentas por el gobierno del partido PNP, dentro de los linderos de la ciudad de Kingston; y Glengoffe, una comunidad rural situada a unas 15 millas de Kingston. Nannyville cumplía con todos los requisitos requeridos, incluso estar afiliada al partido PNP. Glengoffe se seleccionó como resultado de solicitudes hechas por un trabajador de la comunidad que estaba desarrollando un programa de horticultura para mujeres. Este proyecto requeria entrenar a las mujeres para que construyeran y mantuvieran invernaderos, pero él no disponía de fondos para iniciar un programa especial de entrenamiento. La Collective decidió entonces reclutar a cinco mujeres de Glengoffe, por lo menos temporalmente. (Como se consideraba que Glengoffe estaba demasiado distante geográficamente para que el acceso a las áreas de construcción fuera fácil, el proyecto de horticultura prometió dar trabajo a las mujeres. Pero al final este proyecto no se llevó a cabo y las candidatas terminaron en necesidad de una colocación.)

Cuando la ampliación comenzó, surgieron preocupaciones de carácter político. Se temió que ocurrieran actos de violencia cuando las partidarias de PNP entraran a Tivoli o las afiliadas a JLP fueran a Nannyville. Al principio se asumió que iban a necesitarse dos Collectives. Pero a tal división se opusieron fuertemente no sólo las recién reclutadas sino también las que eran miembros originales de la Collective. Ahora las reuniones mensuales tienen lugar en un territorio neutral: las oficinas del centro CRDC. Una de las mujeres lo definió asi: "Nosotras no tenemos nada que ver con la política de la tribu. Eso dejémoselo a los hombres. Nosotras las mujeres estamos hartas de eso."

"Antes de hacerme miembro de la Women's Constructive Collective, yo sufria en mi casa de la frustración de depender de mi familia para cualquier cosa que necesitara; no podia conseguir trabajo y siempre me preguntaba qué sería posible hacer para volverme independiente."

Sharon tenía 25 años y dos hijos cuando se unió a la Collective. Siempre había sido muy 

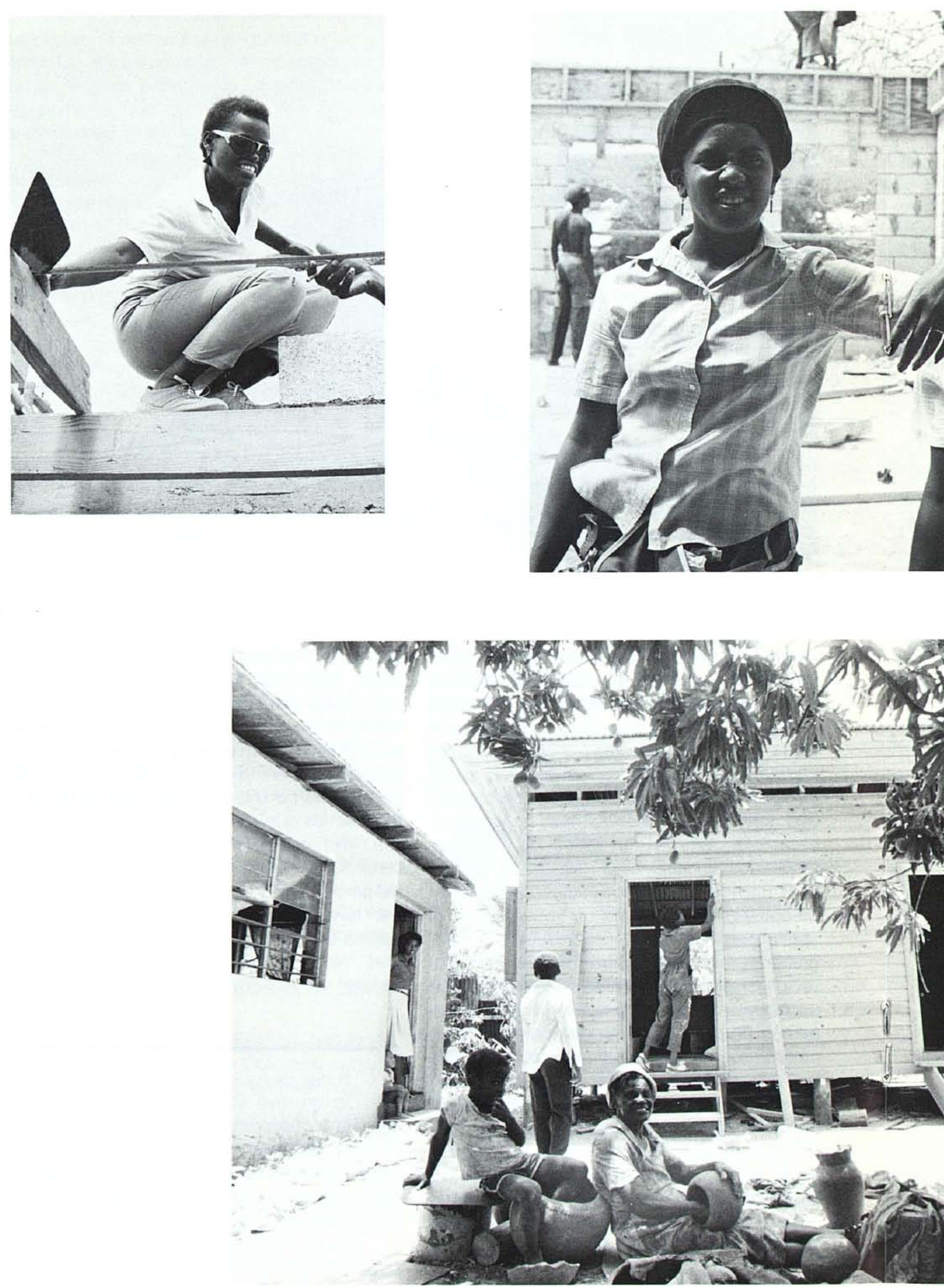

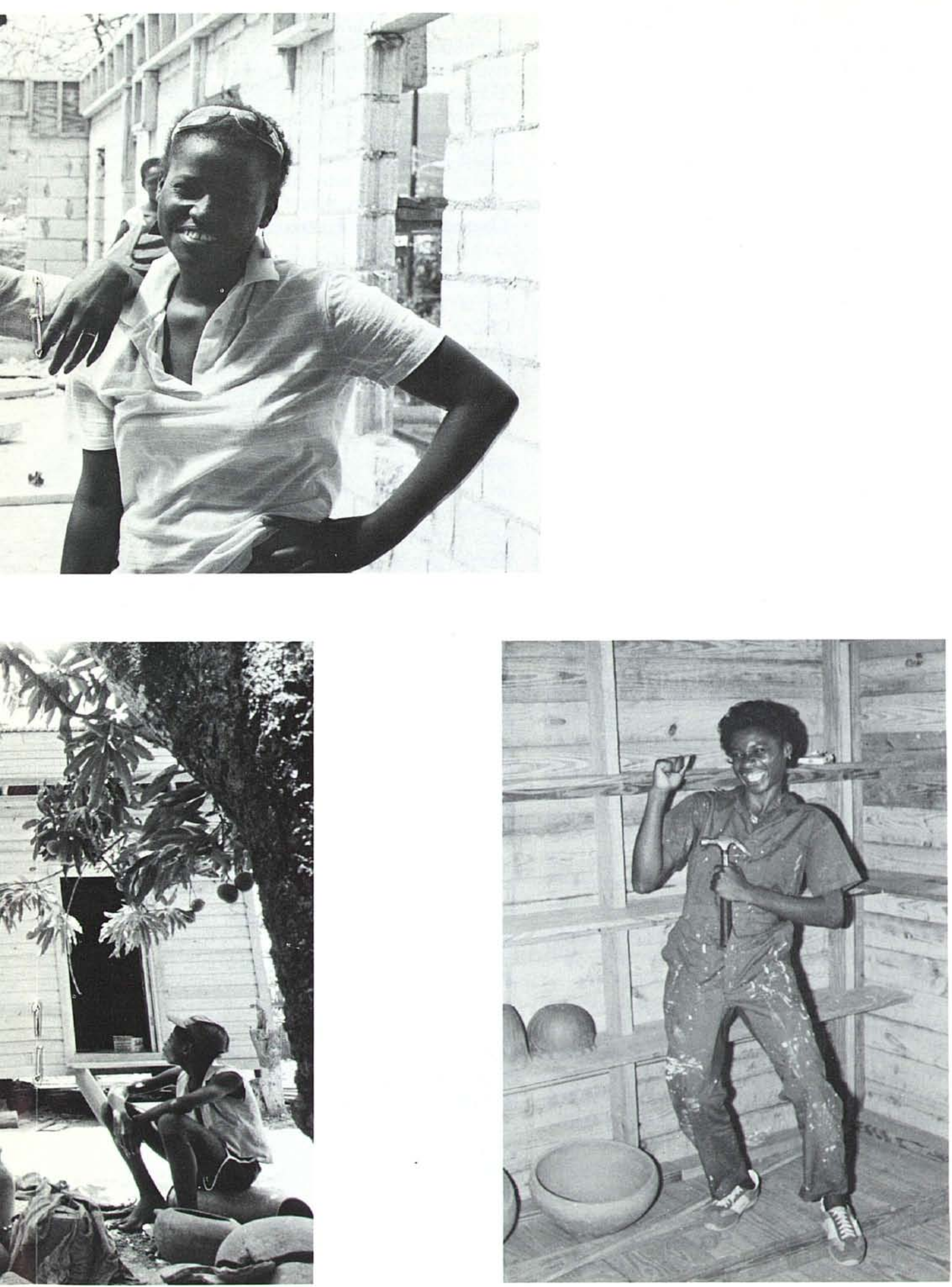
cercana a su abuelo, quien la apoyaba para que construyera carretillas y arreglara con sus herramientas todas las cosas que se rompieran. El padre de Sharon trabajaba también en construcción y a veces la llevaba a los sitios de las edificaciones. Cuando ella le habló por primera vez de la Collective, él se rio; pero ahora le encanta oír hablar de 'uno por dos' o 'dos por cuatro.' "Si yo bubiera sido un muchacho habría trabajado en el Departamento de Obras Públicas ayundando a arreglar los caminos. Pero las Obras Públicas no parece que empleen mujeres, excepto como secretarias."

Como su "baby father" hablaba en contra de que ella se uniera a la Collective, "yo le dije que sólo estaba martillando unas cuantas puntillas y no nombré el cemento. Cuando llevé a casa el banquillo que hice, él comenzó a llamarme carpintera; y ahora cada vez que algo se rompe me piden a mi que lo arregle."

Sharon ha aprendido a levantar una casa entera en madera; sabe cómo usar los taladros eléctricos, las escuadras, las mandarrias, los serruchos y los martillos. Se ríe al decir: "Yo nunca me imaginé que iba a llegar a tumbar muros y todo eso...i pero me encanta!"

Sharon, que viene de Nannyville, ingresó en la Fase III y se siente muy orgullosa de la unidad entre las mujeres de la Collective: "Nosotras somos todas como hermanas; y no me explico qué papel podría desempeñar aqui la política. No veo cómo podría ayudarnos. A mi me parece muy bien que todas seamos mujeres de sectores políticos diferentes... una mezcla de todo."

En junio de 1984, cuando el proyecto casi completaba un año, los miembros de la Collective decidieron que aumentar más el número de miembros no parecia prudente, pues se notaba cierta disminución en la industria de la construcción. La edificación de casas comenzó a declinar más de un 30 por ciento en 1984, y el presupuesto del Ministerio de Vivendas se redujo ¡de treinta millones (moneda Jamaicana) a J\$100! En sonsecuencia, se decidió que lo mejor era consolidarse y enfocar los esfuerzos hacia el mejoramiento de los conocimientos de las mujeres que ya pertenecian a la Collective. Habia mucho camino por recorrer antes de que cualquiera de ellas pudiera considerarse bien preparada y capaz de trabajar sin que se la supervisara. Pero este vuelco también requeriría fondos adicionales. Estos fondos, indispensables para implementar el programa de preparación más avanzada, fueron provistos por la Inter-American Foundation.

\section{Organización Estructural}

Desde 1984, el centro CRDC ha servido como organismo matriz ("parent organization") de la Women's Construction Collective. El CRDC administra los fondos internacionales, emplea personal, provee oficinas y, a la vez, proporciona una guía legal y estructural para la Collective hasta que ésta llegue a ser una entidad legal independiente.

La expansión de la Collective condujo a definir de nuevo su papel y a la creación de una nueva organización estructural. El objetivo era incrementar la capacidad de la Collective para gobernarse a si misma y para que así disminuyera la necesidad de depender de las opiniones de la coordinadora y de la codirectora, lo cual ofrecía la oportunidad de que cada mujer tuviera más responsabilidades.

El problema de la dependencia ha sido una cuestión crítica desde que se formó la Collective. El primer grupo de mujeres gastó un tiempo considerable discutiéndolo y hasta expulsó a una mujer por su pasividad casi total y por su imposibilidad, o falta de voluntad, para asumir responsabilidades. Un ejemplo típico de este problema fue el tremendo esfuerzo que requirió abrir una cuenta bancaria a nombre de la Collective. Después de tres meses de iniciado el proyecto, la coordinadora rehusó ir al banco a conseguir las formas necesarias arguyendo que los miembros debian asumir esa responsabilidad. Varias mujeres fueron finalmente seleccionadas para llevar a cabo este asunto bancario; sin embargo, dos meses fueron necesarios para que consolidaran y coordinaran sus esfuerzos hasta lograr abrir una cuenta bancaria (lo cual le habria tomado diez minutos a la coordinadora). Al final de los dos meses, al menos algunas de las mujeres habían aprendido a tratar con los empleados del banco y a abrir una cuenta bancaria.

Uno de los resultados de concentrar la atención en la dependencia, fue que el grupo tomó la decisión de establecer un criterio para 
seleccionar las nuevas mujeres que se reclutarian al entrar en la Fase III del proyecto. EI objetivo era la eliminación oportuna de quienes no estuvieran muy motivadas. Como parte del procedimiento para hacer la selección, los miembros crearon dos cuestionarios o pruebas de conocimiento: uno, para inglés; el otro, para matemáticas. $Y$ cada recluta potencial tenía que someterse a tomarlos. Los cuestionarios incluian la pregunta de por qué la aplicante quería ser una obrera en construcción; y también otras preguntas específicas relacionadas con avalúos y medidas, usando ejemplos de construcción.

Al principio las mujeres eligieron lo siguiente: una líder del grupo, quien dirigiría las reuniones y representaría la voz de la Collective: una secretaria y una encarcargada de las relaciones públicas. Además, la mayoría de las mujeres que trabajaban juntas en una construcción determinada, elegía una lider que las representara ante el contratista y que hablara por ellas en las reuniones mensuales. En un grupo se dessarrolló un sistema rotativo de representante.

Al final del primer año, la líder de la Collective y la secretaria comenzaron a quejarse de que todo se les encomendaba a ellas y de que "las mujeres nos maldicen y nos hacen la vida dificil cuando nosotras les pedimos que hagan algunas cosas." Entonces la Collective acordó, por unanimidad, el nombramiento de un Comité Ejecutivo cuyas responsabilidades de trabajo se definirian claramente. Como resultado de ello, la Collective tiene ahora un Comité Ejecutivo permanente: éste consiste de cinco mujeres que se reunen regularmente con la coordinadora del proyecto.

Millicent es Presidente de la Collective no obstante ser uno de sus miembros más jóvenes. Tenia sólo 18 años cuando ingresó a la Fase I. Ahora vive en Tivoli, en un apartamento de dos dormitorios que comparte con once miembros de su familia. Pero la mayor parte de su infancia la habia pasado con una tía que era granjera.

Cuando oyó por primera vez lo de la Collective, pensó que todo eso era "un poco raro" pero que nada perdía con ensayar. "Cuando me nombraron lider del grupo, compredi que se esperaba mucho de mi; y yo sabía que eso traeria disgustos porque a algunas de las muchachas les encantan las discusiones interminables. Cuando comenzamos a pagarle dinero al fondo de herramientas y a organizar actividades para conseguir dinero, surgieron muchos problemas. Parecía que todas tenían una excusa para no hacer algo. Pero una de las cosas que más me gustan del grupo es que todas somos abiertas y asi pueden hablarse las cosas."

Millicent caminaba tres millas para llegar a su primer trabajo de construcción. "Yo estaba un poco miedosa al principio porque los hombres se veian rudos; pero después de hablar con ellos me senti diferente porque siempre querian trabajar con nosotras. En una ocasión, los hombres que eran albañiles no fueron a trabajar y entonces nosotras ayudamos con el vaciado. Llenamos los primeros cimientos y pusimos las primeras capas de ladrillos. Cuando vinieron los albañiles al dia siguiente, se asombraron y dijeron que ellos no sabian que las mujeres podian hacer eso."

La transición necesaria para que la Collective pase de depender de una dirección externa a tener su independencia, ha ido sucediendo relativamente despacio. Al comienzo, la coordinadora del proyecto hacia la mayoria de las decisiones esenciales acerca de selección de participantes, contenido del programa de entrenamiento, consecusión de trabajos, etc. Cuando la codirectora se unió a la Collective, se decidió seleccionar dos miembros de la Collective para entrenarlas como directoras. Así, una mujer que había sido líder del grupo ahora funciona como Presidente de la Collective. La otra mujer seleccionada había ingresado al proyecto durante la Fase III y venia de Nannyville.

Cuando la coordinadora terminó su año con la Collective y se fue, hubo un acuerdo general acerca de que ya era tiempo de que las participantes mismas se hicieran cargo de la dirección diaria de la Collective. Las que habían sido entrenadas como directoras, ocuparon la posición que dejaba la codirectora y se encargaron de la contabilidad, las colocaciones, el control de trabajo en las edificaciones y otros aspectos diversos de la organización. A estas les ayudan otros miembros del Comité Ejecutivo recientemente nombrado. 


\section{Nuevas Iniciativas}

Una medida tomada para estimular mayor independencia, fue establecer negocios propios de la Collective: un negocio de reparación y mantenimiento y un taller de carpintería. Las mujeres que no estén empleadas por contratistas atienden los negocios, en un ciclo rotatorio de cinco a ocho semanas; se ocupan del taller construyendo piezas de madera como puertas, estantes, ventanas, etc., o si no, haciendo trabajos de reparación por toda el área de Kingston. El taller lo dirige un carpintero empleado por la Collective; los trabajos de reparación, que se hacen afuera, los supervisa un experto que antes trabajaba para el gobierno como instructor de construcción.

Los trabajos de reparación y mantenimiento surgieron como respuesta a una clara necesidad de que existieran firmas que pudieran hacerse cargo de pequeñas reparaciones domésticas, tales como reponer o colocar puertas, arreglar ventanas, instalar estantes, etc. Además, entre esa clientela potencial había mujeres que se sentían más seguras si era una mujer la que venía a trabajar dentro de sus casas. El entrenamiento en este proyecto se paga por sí mismo con lo que se gana de los clientes. Durante su entrenamiento, a cada mujer se le paga como ayudante de gremio, de acuerdo con las tarifas establecidas en la industria; pero se espera que ella lleve a cabo un proyecto individual, tal como construír algo que la Collective necesite. Las ganancias de los negocios se colocan en el fondo de la Collective. El taller, por ejemplo, fue construído por la Collective con dineros obtenidos cuando 'el negocio' edificó una casa de madera para Ma Lou, uno de los más famosos ceramistas de Jamaica.

El capital inicial para 'los negocios' se recibió del fondo de la Fundación Interamericana; este dinero permitió mejorar el entrenamiento, adquirir equipo y comprar dos vehículos. A su turno, los vehículos disminuyeron la necesidad que tenía la Collective de depender de una o dos personas que podían conducir el camión del centro CDRC, y sirvió de estímulo para que más mujeres aprendieran a conducir.

A este punto, la Collective funciona a tantos niveles que la necesidad de una coordinación eficaz se ha hecho más evidente.

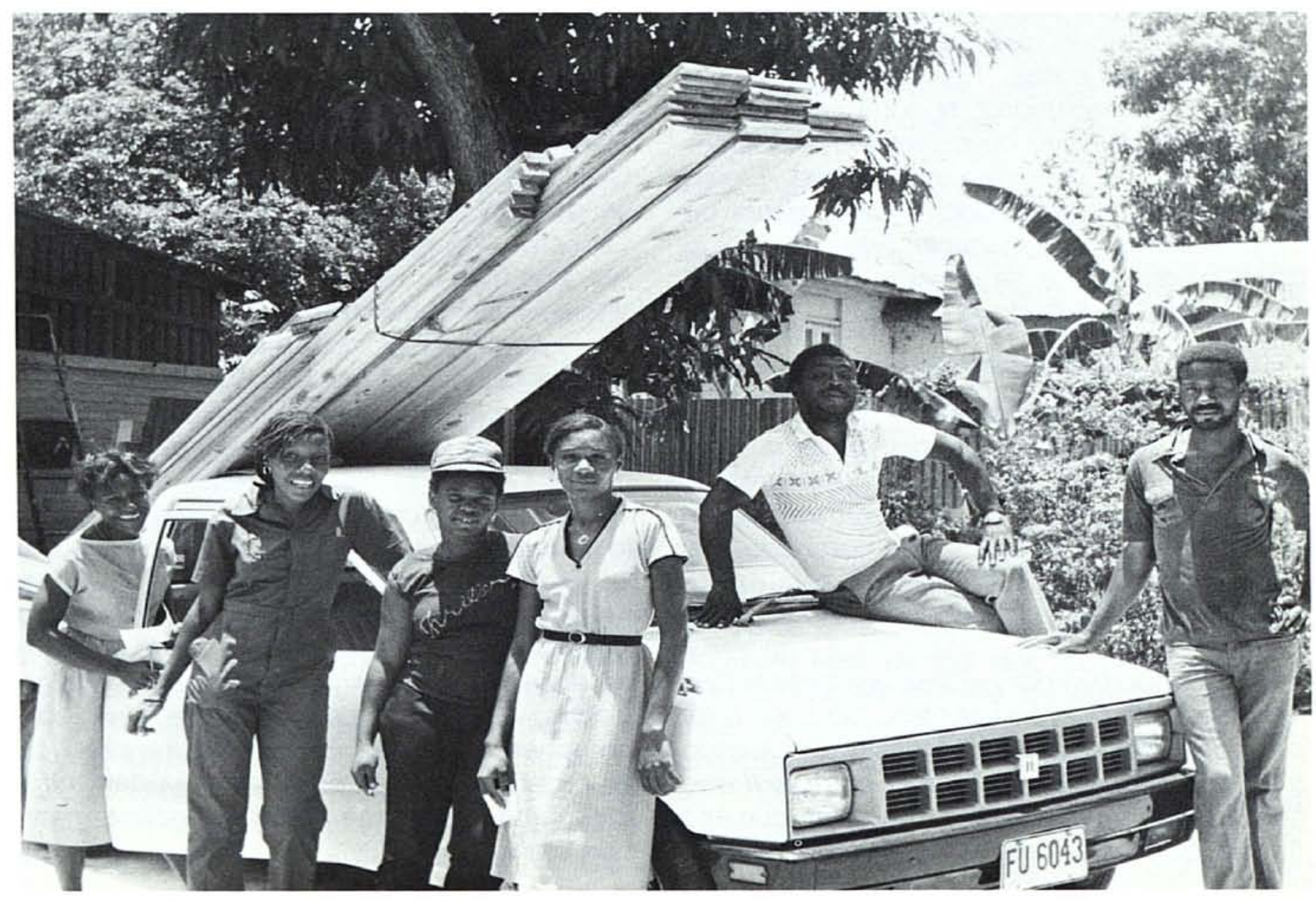


Entonces, hace poco, el personal del centro CRDC y los miembros de la Women's Constructive Collective encargados del taller, del negocio de reparaciones y de la oficina, resolvieron reunirse los viernes por la tarde para tener una 'sesión de crítica' abierta; el propósito fue discutir las actividades de la semana anterior y distribuír los trabajos de la semana siguiente. $Y$ no hay duda de que tanto la estructura de la organización como la planeación de las cuestiones administrativas de la Collective, seguirán cambiando durante los próximos dos o tres años, hasta que finalmente encuentren una forma permanente.

\section{Apoyo para las Mujeres en Entrenamiento}

El hecho de haber enfocado el proyecto hacia la industria parece ser, en gran parte, responsable de la alta rata de empleos logrados; pero el énfasis puesto en la participación de la comunidad, que trajo consigo su apoyo, no fue menos importante para lograr la cohesión entre los miembros del grupo. El apoyo de la comunidad desempeñó un papel definitivo en la transición de desempleadas a empleadas en construcción; pues este trabajo, en una sociedad dominada por el hombre, habia sido inconcebible para la mujer.

El apoyo familiar también era necesario pero no siempre fue logrado; tomó tiempo y educación. La Presidenta actual de la Collective, Millicent Powell, lo expresó así: "A comienzo, mis padres no eran partidarios de que yo hiciera trabajo de construcción ya que ellos habían invertido dinero enviándome a una escuela mercantil." Otras mujeres describieron cómo sus familias habían creído que se trataba de una broma pues no podian concebir que una mujer pensara seriamente en trabajar como obrero de construcción: "Todo el mundo sabía que ese era un trabajo de hombres." A algunas no se les permitió ingresar porque sus "baby fathers" decian que "no querían dos hombres en la casa." $Y$, en dos ocasiones, el conflicto llegó al punto de romper las relaciones.

Un estudiante universitario que entrevistó a algunas afiliadas a la Collective, descubrió algo muy interesante: que ellas habian recibido mucho más apoyo de las mujeres de la familia que de los hombres. Este apoyo femenino se notó también en mujeres provenientes de organizaciones religiosas. En contraste, un pastor de la iglesia se opuso totalmente al proyecto porque pensaba que facilitaría el que las mujeres "llevaran pantalones."

Sin embargo, el mayor apoyo sicológico emanó tal vez de las mujeres que eran miembros de la Collective. El grupo se reúne un domingo del mes. Allí no sólo comparten sus experiencias en el trabajo y las reacciones de sus familias, sino que organizan eventos de grupo como equipos deportivos y paseos, todo lo cual hace más fuerte la unión de los miembros. Otra iniciativa de la Collective fue lanzar una campaña de divulgación; ésta se hizo a través de periódicos, televisión y radio. Además se usó una cinta video donde se mostraban las mujeres trabajando y hablando de sus experiencias, a la vez que se describia el modelo inicial de entrenamiento usado por la Collective en sus primeras etapas.

Las mujeres necesitan no sólo la fortaleza y la voluntad para entrar a un campo donde tradicionalmente han dominado los hombres, sino además los medios financieros. Porque es prácticamente imposible, por ejemplo, conseguir trabajo como ayudante de un carpintero si uno no tiene un serrucho. Por esta razón, la Collective mantiene un fondo para herramientas. Cuando una mujer va a ser entrevistada, se le prestan las herramientas necesarias. Si le dan el trabajo, se queda con las herramientas; y cuando comienza a ganar un salario, ella le paga al fondo el precio de las herramientas. Esa mujer tiene que haber pagado la totalidad de las herramientas para que se le acepten otros préstamos o para poder ingresar a otros programas adicionales de entrenamiento. Las herramientas no son muy costosas cuando se compran al por mayor; así que la operación del préstamo y el reembolso al fondo, manteniendo el dinero en una cuenta bancaria que produzca interés, hace posible prestarles herramientas nuevas $\sin$ tener que exigirles un respaldo del préstamo.

En la actualidad, el miembro de la Collective que quiera participar en un programa más avanzado, puede dirigirse al Comité Ejecutivo. Si éste considera que tal entrenamiento beneficia tanto a la mujer como a la Collective y si hay dinero para los préstamos necesarios, la solicitud de entrenamiento se aprueba.

La Collective provee además el dinero de autobús para que las mujeres asistan a las 
reuniones mensuales y a cualquier entrenamiento aprobado por la Collective. Esto es especialmente importante para las mujeres que no estén trabajando, bien sea porque no haya sido posible colocarlas o porque se encuentren en la transición de un trabajo a otro. En algunas ocasiones, el fondo de la Collective, que está manejado por el Comité Ejecutivo, se ha usado para hacer préstamos relacionados con enfermedades o cuidados infantiles; pero esto ha sido desusual y se evita a toda costa porque la Collective no tiene como objectivo convertirse en una organización de asistencia social.

\section{Resultados}

Lurl se unió a la Collective en mayo de 1984, después de pasar por el proceso de selección desarrollado por los miembros iniciales de la Collective. Lo primero que se le asignó como miembro fue que hiciera su propia presentación; ella la hizo cubriéndose parcialmente la boca y riéndose nerviosamente, por lo cual parte de lo que dijo no se oyó. Más adelante se supo que no había terminado bachillerato; que mantenía a sus dos hijos; que nunca habia estado empleada y que su aspiración habia sido ser experta en belleza. Como las tentativas en el campo de la belleza no le habian resultado, estaba lista para ensayar cualquier cosa que se presentara. Y lo que se presentó fue la Women's Construction Collective, asi que comenzó su entrenamiento en la Fase III.

\section{Cuando se terminaron las cinco} semanas de entrenamiento, no habia un trabajo disponible para ella debido a unas demoras ocurridas en un proyecto de construcción que habia prometido emplearla. Entonces resolvió trabajar por seis semanas con otras diez mujeres que no recibian salario, en un proyecto de reconstruir un viejo local que vendia licores al por mayor y que vino a convertirse en el centro CRDC y WCC. Durante la última semana de esta práctica, la Collective recibió solicitud de que mandara dos mujeres a entrevistas para trabajo de mantenimiento que se presentaba en una de las compañias más grandes de bauxita o hidrato de aluminio. Lurl fue la primera que se presentó a la entrevista y comenzó a trabajar a la semana siguiente, ganando el salario más alto que jamás haya recibido un miembro de la Collective.

Poco después se eschucharon rumores, que más tarde se confirmaron, de que Lurl se había mudado fuera de su barrio y habia abandonado a su "baby father." Ella pertenecia a una familia campesina muy pobre, de ocho hijos. Cuando habia cumplido 14 años, su madre, que escasamente podía sobrellevar el peso económico de la familia, tomó una decisión: hacer que Lurl se fuera a vivir con un benefactor que se comprometía a pagar su educación escolar. Cuando ella llegó a los 16 años, quedó embarazada por su "benefactor" y abandonó la escuela. A los 18 años era ya la madre de dos niños y la golpeaba constantemente el hombre de quien ella dependia económicamente.

Como resultado de su experiencia, en cuanto Lurl empezó a ganar un salario no vaciló en empacar sus valijas e irse. Ahora vive en otra parroquia con sus dos hijos y una hermana. Como pintora industrial tiene un trabajo estable; y su rendimiento es tan apreciado que quienes la emplean están considerando conseguir otras mujeres más para el equipo de mantenimiento.

Durante su afiliación con la Collective, Sharon, Millicent, Pauline y Lurl tuvieron experiencias muy diferentes. El impacto que a la larga tuvo el proyecto sobre ellas y sobre sus familias, es difícil de determinar; pero otros cambios más inmediatos fueron muy evidentes. En cuanto vieron que podian ganarse la vida en una industria dominada por el hombre, adquirieron mayor confianza en si mismas. Todas cuatro se aferraron a la Collective a tal punto, que dos de ellas resolvieron por sí mismas rechazar cinco ofertas de trabajo en campos tradicionalmente femeninos. Por lo demás, la mayoria de las afiliadas llegó a ser, en forma clara y articulada, la "voz" de la Collective; y todas adquirieron un mayor sentido de responsabilidad tanto individual como de grupo. En el curso de dos años y medio, entre todas las mujeres que dejaron la Collective hubo cuatro que lo hicieron porque estaban encinta. Dos de estas mujeres afirmaron que la preñez habia sido impuesta contra su voluntad porque los "baby fathers" no querian "dos hombres en la casa." Ninguna de estas mujeres llegó a trabajar en obras de construcción ni ha regresado a la Collective. 
El impacto que tuvo la Collective en la industria de la construcción parece haber sido muy positivo. A esto contribuyeron los análisis iniciales que se hicieron para determinar las necesidades de los constructores a nivel de gremio. Por otra parte, el que las participantes del proyecto hubieran aceptado ser entrevistadas para, si eran aprobadas, trabajar por un período de prueba no remunerado, ayudó sin duda a lograr colocaciones. Los reportes de que la violencia ha disminuido y la productividad ha aumentado en las obras donde trabajan miembros de la Collective, parecen estar directamente relacionados con una percepción positiva del papel que las mujeres representan alli. Los constructores y los capataces han observado que la presencia de las mujeres hace que los hombres, casi automáticamente, sean menos abusivos y violentos. Hay además la sensación de que hombres y mujeres tienden a competir unos con otros en el trabajo: las mujeres trabajan para demostrar que "pueden hacerlo tan bien como los hombres," y los hombres tratan de "sobrepasar a las mujeres." Esta forma de competencia inevitablemente estimula la productividad. Otro efecto positivo ha sido la habilidad desarrollada por las mujeres para traspasar los linderos políticos. Algunas mujeres provenientes de comunidades afiliadas a un determinado partido político, han sido colocadas en sectores afiliados al partido opuesto, sin que esto haya presentado ningún problema serio.

Hasta ahora, en el campo de la construcción la mujer no representa una amenaza para el dominio masculino. En ese campo, el número de mujeres es pequeño; y ellas no han alcanzado el nivel de maestria necesario para competir en la consecusión de trabajos como los de subcontratistas. En realidad, todavia están "mandadas" por hombres; y esta puede ser la razón para que no exista una resistencia seria por parte de sus compañeros de trabajo. Sin embargo, a medida que las posiciones son más y más escasas en esta industria, es muy probable que crezca una resistencia. Una mujer se quejó recientemente de que un hombre la habia amenazado en el trabajo, arguyendo que ella estaba quitándole el empleo porque él era hombre y venia del "territorio político correcto" y ella no. Esta mujer opinó que, al menos en el caso citado, el asunto político tenía más prevalencia que el de sexo.
Por otra parte, la publicidad que el proyecto ha recibido localmente ha hecho que el concepto de que las mujeres trabajen en construcción logre mayor aceptación tanto en el trabajo mismo como en la comunidad. Esto último se ha comprobado por la capacidad que los miembros de la Collective tienen para mantener sus trabajos o para encontrar otros, a pesar de la seria disminución de actividad en la industria; además, por las constantes solicitudes de admisión que recibe la Collective.

Aunque la entrada de 34 mujeres competentes en la industria de la construcción a nivel de gremio puede parecer poco significativa, los contratistas que han empleado miembros de la Collective dicen que ahora están empleando más mujeres. Esto puede indicar que tendrán ahora oportunidades de conseguir trabajo muchas de las mil o más mujeres que recibieron entrenamiento en construcción antes de 1980, lo mismo que las que se beneficien de las nuevas instituciones con residencia para entrenamiento abiertas recientemente. También ha producido entusiasmo en la Collective el que en otros paises algunos grupos de mujeres hayan demostrado interés en el proyecto, lo cual se debe primordialmente a la cinta video que se produjo para promulgar las actividades de la Collective.

O sea que, en resumen, durante los dos años y medio en que la Collective ha estado funcionando, ha entrenado a 34 mujeres, el 90 por ciento de las cuales han sido colocadas en trabajos de construcción tales como plomeria, albañileria, carpinteria, instalación eléctrica, pintura y fundición. Más de 15 de estas mujeres han recibido entrenamientos adicionales que van desde conducir un automóvil haste leer planos de construcción. Dos mujeres completaron el curso de Tecnologia para Construcción en el College of Arts, Sciences and Technology (CAST) de Jamaica, y dos miembros han desempeñado la administración diaria del proyecto. Además, la Collective hizo trabajos de reconstrucción para lograr espacio adecuado para sus propias oficinas y para el centro CRDC. Los fondos han crecido y el proyecto inició sus propios negocios para desarrollar una fuente de entradas independiente. 


\section{Miras al Futuro}

El futuro de la Collective no será ciertamente asunto fácil. No obstante los esfuerzos de sus miembros, los efectos de un gran descenso en la industria de la construcción tendrán que sentirse, especialmente en lo concerniente a empleos. La decadencia económica general ha dejado a los clientes potenciales con menos dinero disponible. En consecuencia, ha sido preciso buscar nuevos mercados para el tipo de conocimientos que las mujeres han adquirido y para los más avanzados que están adquiriendo. En este momento, seria prematuro decir si esta es la solución acertada, aunque es evidente que la experiencia obtenida en el negocio del taller ha elevado notablemente el nivel de las mujeres que trabajan en carpintería.

Hasta ahora, la demanda para labores de mantenimiento ha sido muy estimulante, pero no se ha comprobado si lo será a largo plazo ni a cuantas mujeres podrá darles trabajo. A medida que el negocio crezca, será necesario estructurar más aun estas actividades de la Collective. Por lo tanto, a partir de marzo de 1986 la organización se ha denominado oficialmente Kingston Women's Construction Collective, Ltd., o sea que es una compañia reconocida legalmente en Jamaica.

Sin embargo, la Collective está lejos de ser independiente. El proyecto total continúa bajo la supervisión de la coordinadora; y el centro CRDC continúa administrando los fondos básicos, contratando los empleados a través de su organización y facilitando las oficinas.

Desde su comienzo, la Collective ha dependido de donaciones extranjeras. Pero en mayo de 1986 estas ayudas gratuitas expiran. Y los negocios tendrán que crecer para que, como fuentes de ingresos, sean suficientes para que la Collective se sostenga a sí misma. Los miembros opinan enfáticamente que la Collective debe continuar, no sólo por el beneficio que ofrece a las mujeres ligadas a ella sino porque el entrenamiento en construcción, a nivel de principiantes y de avanzadas en el campo, no se les ofrece a las mujeres de la isla en las mismas condiciones en que se les ofrece a los hombres. Como se mencionó antes, el gobierno abrió recientemente un centro para entrenamiento en construcción, con derecho a residencia, llamado Port More Heart Academy. En teoria, esta institución acepta mujeres como estudiantes durante el dia. Pero la realidad es que esa limitación hace que sólo puedan asistir mujeres que vivan en el vecindario inmediato. Un dato irónico es que seis miembros de la Collective, que viven lejos de donde está hoy esa Academia, ayudaron a construírla. Una solución considerada por la Collective para solucionar este problema es establecer una residencia para mujeres en entrenamiento que esté situada cerca de la Academia. Otra solución sería la expansión de la Collective, para incluír mujeras que hayan sido entrenadas en construcción pero que no hayan tenido ayuda para conseguir trabajo ni para avanzar en su entrenamiento. Cualquiera de estas opciones requiere fondos adicionales.

Para poder afrontar estos problemas críticos, es preciso que la intercomunicación entre la industria y las comunidades continúe ofreciendo la misma flexibilidad. Porque es esa flexibilidad la que ha contribuido fundamentalmente al desarrollo de la Collective.

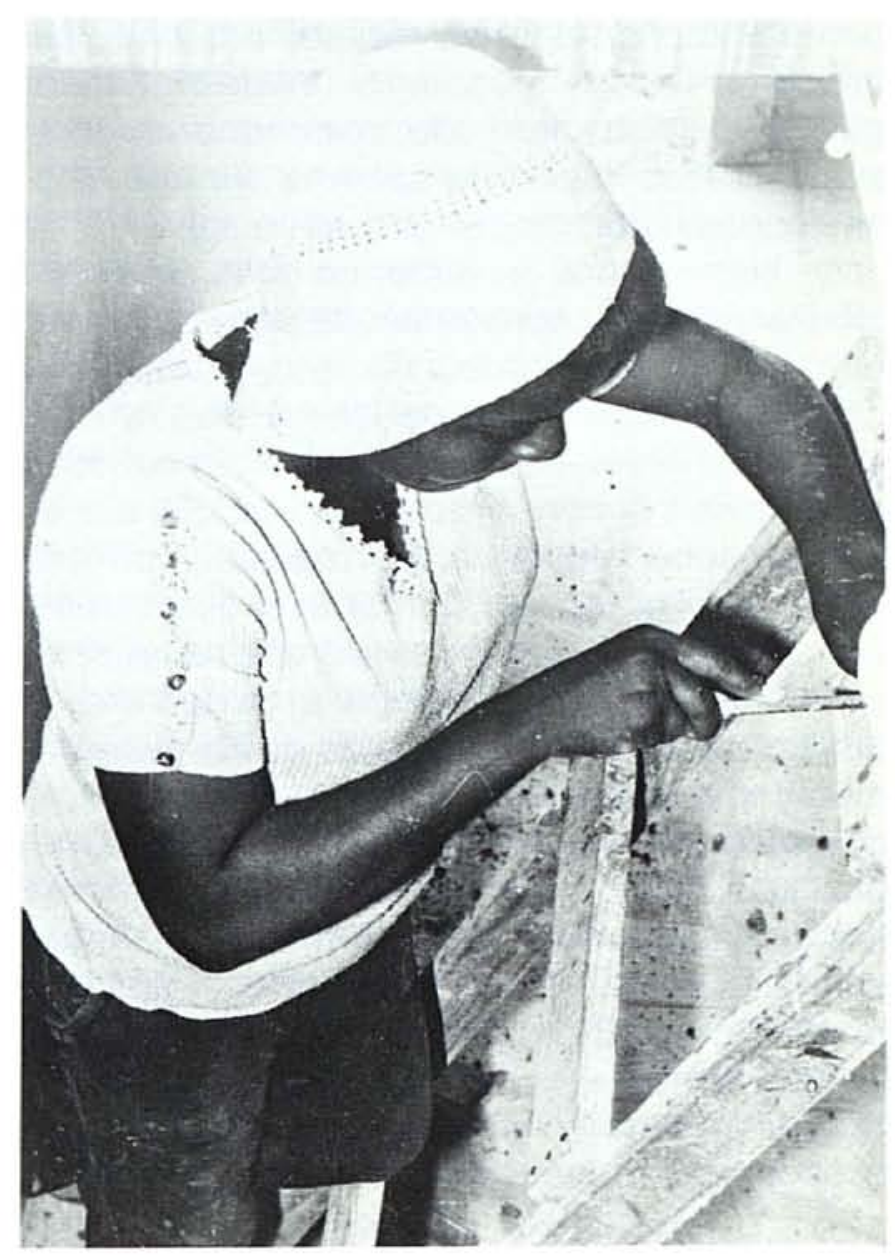




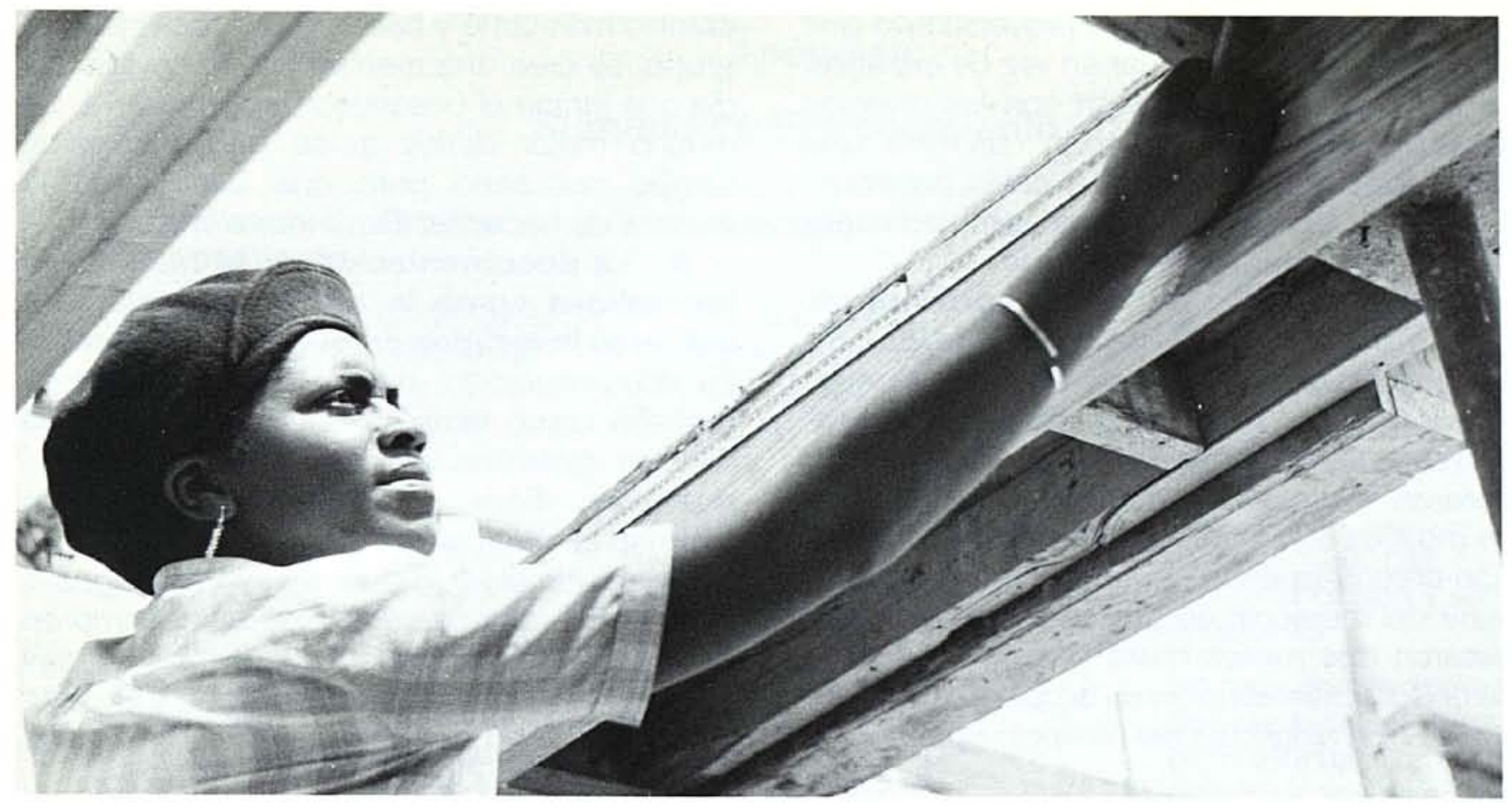

\section{Aprendidas}

1. Un análisis minucioso de la industria es crucial, especialmente si se trata de una industria que tradicionalmente no ha empleado mujeres. Las participantes encontraron empleo porque se las había entrenado para trabajos específicos que estaban disponibles a niveles determinados.

2. Las mujeres deben tener acceso a las herramientas necesarias, sin que eso les represente un gasto antes de comenzar el trabajo. En el caso de este proyecto, no habia trabajo para mujeres que no tuvieran sus propias herramientas. Un fondo giratorio puede asegurar el acceso a las herramientas sin que la mujer necesite un respaldo financiero.

3. La cohesión de los miembros depende en gran parte de ciertos vínculos que unan a las comunidades o barrios, lo cual se logra a través de un cuerpo central como el Working Group. Los trabajadores comunales de Tivoli y el liderazgo local de Nannyville y de Glengoffe, ofrecieron permanente respaldo y estímulo a las mujeres, sobre todo en las primeras etapas. El Working Group logró que esas comunidades ofrecieran su apoyo.

4. Es extremadamente útil tener acceso a instituciones 0 a individuos que quieran y puedan proveer entrenamiento individual. Un programa independiente puede ser tremendamente costoso; y entrena- miento a corto plazo no justifica costosas inversiones en maquinaria y equipo. El Vocational Training Development Institute permitió que los encargados del proyecto intervinieran en la planeación de los programas de entrenamiento y a la vez facilitaron locales bien equipados y bien supervisados.

5. Cuando se trabaja en sectores que políticamente son muy explosivos, el proyecto debe mantener una identidad política “'neutral."' La neutralidad política de los directores del proyecto les permitió penetrar en comunidades de afiliaciones politicas violentamente opuestas, lo mismo que moverse a través de esos linderos territoriales. Lo anterior trajo como consecuencia la cooperación entre las mujeres de estas comunidades tan diferentes.

6. Cuando comienzan a desarrollarse los proyectos, con frecuencia toman un curso muy diferente del que se habia anticipado al presentarlos a las agencias que los financiarian. Por lo tanto, las buenas relaciones con el director que se encarga del proyecto en la agencia financiadora, permiten que haya flexibilidad en cuanto al planeamiento del programa y en cuanto al uso de los fondos. Por ejemplo, después de comenzado este proyecto su expansión fue mucho más rápida de lo que se habia previsto. Sin embargo, en cuanto se movilizaron los fondos necesarios para respaldar este crecimiento, la industria de construcción comenzó a 
decaer; en consecuencia, el proyecto tuvo que enfocarse hacia consolidar en vez de expandir. La adecuada comunicación con las diversas agencias que lo financiaban, permitió que esos cambios se llevaran a cabo paulatinamente y de acuerdo a decisiones tomadas por la Collective.

7. El desarrollo no puede apresurarse. Las mujeres que han dependido de alguien la mayor parte de sus vidas necesitan tiempo suficiente para acostumbrarse a tener responsabilidades propias. Pasaron 18 meses antes de que cualquiera de las mujeres encontrara un trabajo en construcción como resultado de su propia iniciativa. A partir del momento en que se decidió hacerlo, pasaron dos meses hasta que los miembros de la Collective abrieran su propia cuenta bancaria. Si los dirigentes del proyecto optan por el camino más corto y hacen estas cosas para el grupo, se crea una mentalidad de beneficiencia que inhibe el desarrollo de la iniciativa. Es mucho mejor darles a las participantes el tiempo necesario para que encuentren la manera de hacer las cosas por sí mismas.

8. La documentación de la historia es tan valiosa como lo son la energía y el esfuerzo invertidos en que se lleve a cabo. La documentación, no sólo escrita sino fotografiada como también la cinta video de 10 minutos, facilitaron la solicitud de fondos a las agencias. Esta documentación permitió además la divulgación del proyecto, dentro y fuera de Jamaica, lo cual reforzó su impacto. La energia, la involucración, el entusiasmo de estas mujeres, se captan en una forma más evidente a través de una cinta video y de fotografías que en cualquier forma verbal o escrita.

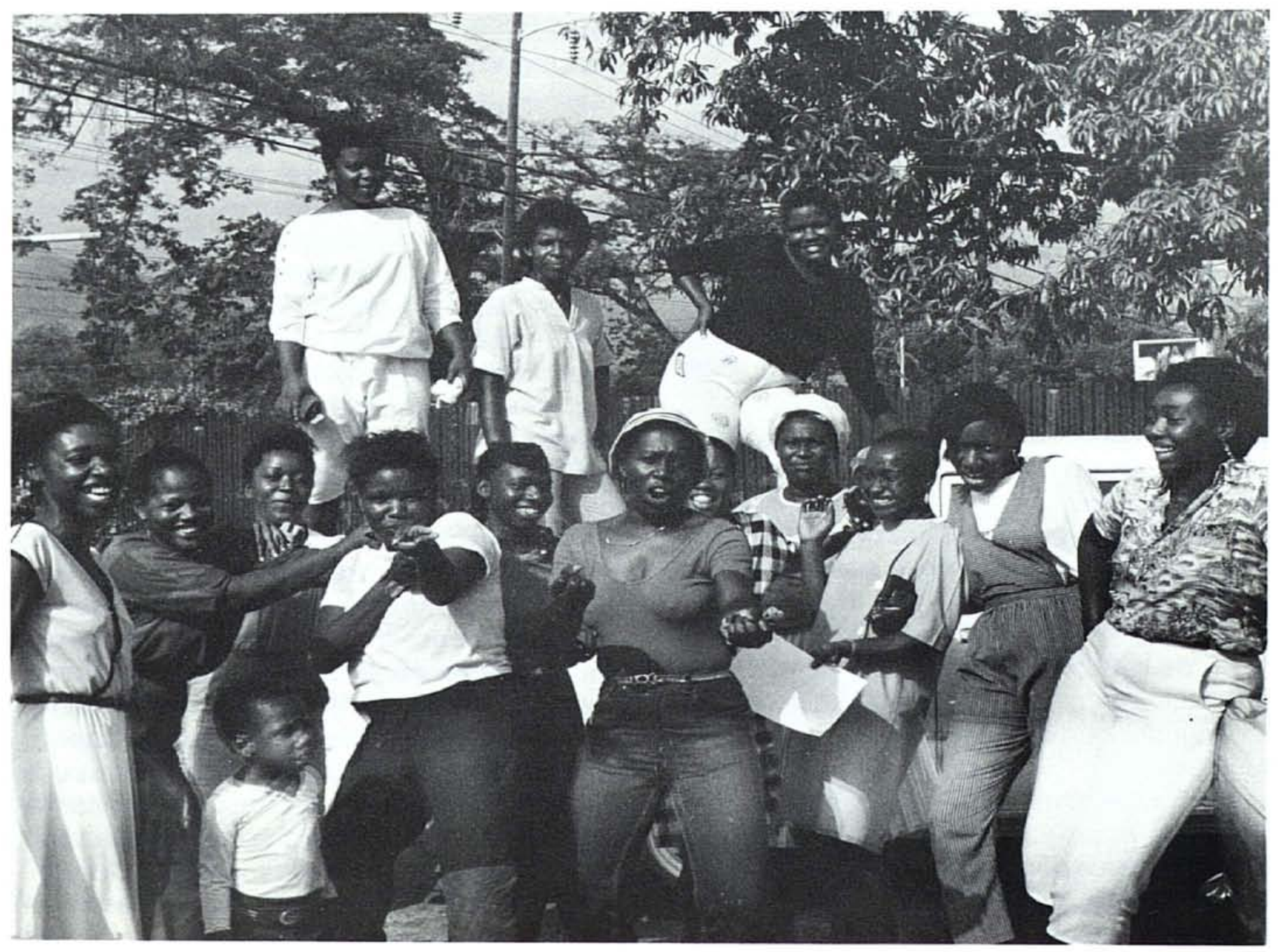




\section{Apéndice}

\section{Sumario de Entrenamiento}

\begin{tabular}{|c|c|c|c|c|}
\hline $\begin{array}{l}\text { Programa de } \\
\text { Entrenamiento }\end{array}$ & Oficios & Duración & $\begin{array}{l}\text { No. de } \\
\text { mujeres }\end{array}$ & $\begin{array}{l}\text { Informatión } \\
\text { Adicional }\end{array}$ \\
\hline $\begin{array}{l}\text { Entrenamiento } \\
\text { Básico I (VTDI) }\end{array}$ & $\begin{array}{l}\text { Carpintería, } \\
\text { albañileria }\end{array}$ & $\begin{array}{l}5 \text { dias por } \\
\text { semana por } 5 \\
\text { semanas }\end{array}$ & 10 & $\begin{array}{l}\text { Aprendieron a cargar y } \\
\text { asentar ladrillos, construír } \\
\text { un muro y terminarlo, } \\
\text { construír un armazón } \\
\text { sencillo y su propio } \\
\text { taburete. }\end{array}$ \\
\hline $\begin{array}{l}\text { Entrenamiento } \\
\text { Básico (VTDI) }\end{array}$ & $\begin{array}{l}\text { Carpintería, } \\
\text { albañileria }\end{array}$ & $\begin{array}{l}5 \text { dias por } \\
\text { semana por } 5 \\
\text { semanas }\end{array}$ & 15 & $\begin{array}{l}\text { Como arriba más } \\
\text { plomería básica y ajuste } \\
\text { de tubería }\end{array}$ \\
\hline $\begin{array}{l}\text { Mantenimiento } \\
\text { general de } \\
\text { edificios I } \\
\text { (CRDC) }\end{array}$ & $\begin{array}{l}\text { Introducción a } \\
\text { plomeria, carpintería, } \\
\text { albañileria, } \\
\text { electricidad, pintura } \\
\text { y mantenimiento de } \\
\text { aire acondicionado }\end{array}$ & $\begin{array}{l}1 \text { dia, } 1 \text { sesión } \\
\text { nocturna, por } \\
\text { semana por } 12 \\
\text { semanas }\end{array}$ & 5 & $\begin{array}{l}\text { No muy satisfactorio } \\
\text { porque casi todos los } \\
\text { participantes eran } \\
\text { hombres con experiencia } \\
\text { previa. Se hizo asi por } \\
\text { falta de fondos para una } \\
\text { alternativa }\end{array}$ \\
\hline $\begin{array}{l}\text { Mantenimiento } \\
\text { general de } \\
\text { edificios ॥ } \\
\text { (CRDC) }\end{array}$ & Como el anterior & Como el anterior & 4 & Como el anterior \\
\hline $\begin{array}{l}\text { Proyecto vivo } \\
\text { de oficinas } \\
\text { CRDCMCC }\end{array}$ & $\begin{array}{l}\text { Carpinteria, } \\
\text { albañilería, } \\
\text { electricidad }\end{array}$ & $\begin{array}{l}5 \text { días por } \\
\text { semana por } 6 \\
\text { semanas }\end{array}$ & 12 & $\begin{array}{l}\text { Demostró ser muy valioso } \\
\text { para emplearse, en } \\
\text { especial para mujeres } \\
\text { que aprendieron pintura }\end{array}$ \\
\hline $\begin{array}{l}\text { WCC Taller de } \\
\text { carpintería }\end{array}$ & $\begin{array}{l}\text { Carpintería, pintura, } \\
\text { avalúos }\end{array}$ & $\begin{array}{l}5 \text { dias por } \\
\text { semana en } \\
\text { forma } \\
\text { permanente }\end{array}$ & $\begin{array}{l}2 \text { ó } 3 \\
\text { a la vez }\end{array}$ & $\begin{array}{l}\text { El experto clave es un } \\
\text { carpintero. El taller se } \\
\text { mantiene solo y las } \\
\text { mujeres aprenden } \\
\text { además cómo manejar } \\
\text { un negocio }\end{array}$ \\
\hline $\begin{array}{l}\text { WCC Negocio } \\
\text { de Reparaciones }\end{array}$ & $\begin{array}{l}\text { Carpintería, } \\
\text { albañilería, fundición, } \\
\text { pintura, avalúos }\end{array}$ & $\begin{array}{l}\text { Depende del } \\
\text { trabajo }\end{array}$ & $\begin{array}{l}\text { variable } \\
2-7\end{array}$ & $\begin{array}{l}\text { Los trabajos varian desde } \\
\text { construir casas de } \\
\text { madera completas hasta } \\
\text { reparaciones } \\
\text { relativamente sencillas }\end{array}$ \\
\hline $\begin{array}{l}\text { Práctica de } \\
\text { oficina y manejo } \\
\text { del proyecto }\end{array}$ & $\begin{array}{l}\text { Contabilidad, } \\
\text { colocaciones }\end{array}$ & $\begin{array}{l}\text { Tiempo } \\
\text { completo } \\
\text { permanente }\end{array}$ & 2 & $\begin{array}{l}\text { Entrenamiento provisto } \\
\text { por el personal de CRDC }\end{array}$ \\
\hline $\begin{array}{l}\text { Tecnologia } \\
\text { general de } \\
\text { construcción } \\
\text { (CAST) }\end{array}$ & $\begin{array}{l}\text { Dibujo de } \\
\text { construcción, física, } \\
\text { tecnologia de } \\
\text { construcción, } \\
\text { matemáticas, inglés }\end{array}$ & $\begin{array}{l}1 \text { dia y } 2 \\
\text { sesiones } \\
\text { nocturnas por } \\
\text { semana por } 1 \\
\text { año }\end{array}$ & 2 & $\begin{array}{l}\text { Permite acceso a niveles } \\
\text { más altos de } \\
\text { entrenamiento y a } \\
\text { programas de } \\
\text { entrenamiento en } \\
\text { construcción }\end{array}$ \\
\hline
\end{tabular}




\begin{tabular}{|c|c|c|c|c|}
\hline Planos (CRDC) & $\begin{array}{l}\text { Lectura e } \\
\text { interpretación } \\
\text { de planos }\end{array}$ & $\begin{array}{l}1 \text { sesión } \\
\text { nocturna por } \\
\text { semana por } 12 \\
\text { semanas }\end{array}$ & 4 & \\
\hline $\begin{array}{l}\text { Conducir } \\
\text { automóvil } \\
\text { (instrucción } \\
\text { individual) }\end{array}$ & $\begin{array}{l}\text { Conducción de } \\
\text { automóvil }\end{array}$ & Variable & 3 & Invaluable \\
\hline $\begin{array}{l}\text { Mecánica de } \\
\text { automóvil } \\
\text { (instrucción } \\
\text { individual) }\end{array}$ & $\begin{array}{l}\text { Mecánica y } \\
\text { mantenimiento } \\
\text { básico de } \\
\text { automóviles }\end{array}$ & $\begin{array}{l}\text { Sábados por la } \\
\text { tarde por } 8 \\
\text { semanas }\end{array}$ & 3 & $\begin{array}{l}\text { Propósito: rebajar el costo } \\
\text { de mantenimiento de } \\
\text { vehículos }\end{array}$ \\
\hline $\begin{array}{l}\text { Contabilidad y } \\
\text { conocimientos } \\
\text { de secretariado } \\
\text { (Commercial } \\
\text { Business } \\
\text { College) }\end{array}$ & $\begin{array}{l}\text { Mecanografia, } \\
\text { taquigrafía, inglés }\end{array}$ & $\begin{array}{l}2 \text { sesiones } \\
\text { nocturnas por } \\
\text { semana por } 1 \\
\text { año }\end{array}$ & 1 & \\
\hline $\begin{array}{l}\text { Teatro } \\
\text { (Sistren-Women's } \\
\text { Theatre Group) }\end{array}$ & $\begin{array}{l}\text { Explicación a través } \\
\text { del teatro de temas } \\
\text { que afectan a la } \\
\text { mujer }\end{array}$ & 3 sábados & 2 & \\
\hline $\begin{array}{l}\text { Primeros auxilios } \\
\text { (Blue Cross) }\end{array}$ & $\begin{array}{l}\text { Primeros auxilios en } \\
\text { general }\end{array}$ & $\begin{array}{l}2 \text { sesiones } \\
\text { nocturnas por } \\
\text { semana }\end{array}$ & 7 & \\
\hline $\begin{array}{l}\text { Experiencia } \\
\text { práctica }\end{array}$ & $\begin{array}{l}\text { Incrementar } \\
\text { conocimientos del } \\
\text { oficio en sitios donde } \\
\text { están trabajando } \\
\text { mujeres }\end{array}$ & $\begin{array}{l}\text { Tiempo } \\
\text { completo, } \\
\text { indeterminado }\end{array}$ & 2 & $\begin{array}{l}\text { La calidad depende de } \\
\text { los hombres que sean } \\
\text { líderes o capataces, pero } \\
\text { tal vez la forma más } \\
\text { efectiva de entrenamiento } \\
\text { a largo plazo }\end{array}$ \\
\hline $\begin{array}{l}\text { Hacer más } \\
\text { seguras las } \\
\text { casas de } \\
\text { madera (CRDC) }\end{array}$ & $\begin{array}{l}\text { Carpintería, } \\
\text { albañileria }\end{array}$ & $\begin{array}{l}1 \text { semana de } \\
\text { taller }\end{array}$ & 2 & $\begin{array}{l}\text { Este fue un curso de } \\
\text { introducción. Los planes } \\
\text { a largo plazo incluyen } \\
\text { mujeres como } \\
\text { instructoras en programas } \\
\text { avanzados }\end{array}$ \\
\hline
\end{tabular}


Diseño: Ann Leonard

Tipografía: Village Type and Graphics

Fotografia: Ruth Mcleod

Imprenta: Graphic Impressions, Inc.

Traducción: Josefina Lleras

Tanto sus comentarios como sus ideas sobre proyectos que puedan ser incluídos en futuros números de SEEDS, son bienvenidos. Si usted desea ejemplares adicionales de este número o le interesa que se le incluya en la lista de quienes reciben a SEEDS, sirvase escribir a:

Ann Leonard, Editor SEEDS

P.O. Box 3923

Grand Central Station

New York, New York 10163 U.S.A. 


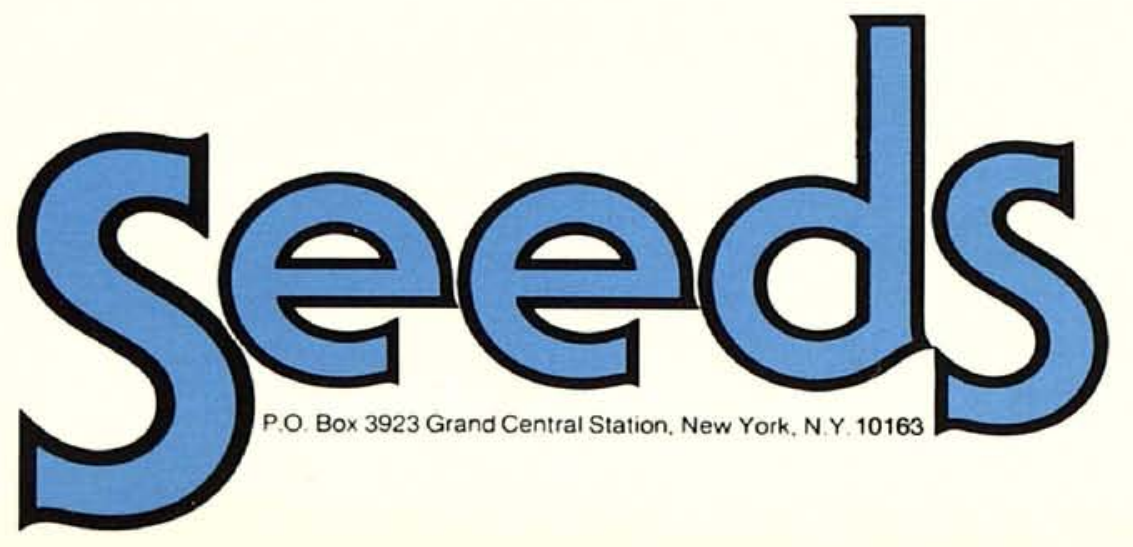

